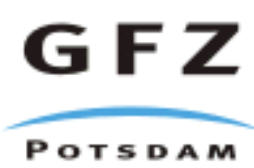

Originally published as:

Milsch, H., Seibt, A., Spangenberg, E. (2009): Long-term petrophysical investigations on geothermal reservoir rocks at simulated in situ conditions. - Transport in Porous Media, 77, 1, $59-78$

DOI: $10.1007 / s 11242-008-9261-5$ 


\title{
Long-term Petrophysical Investigations on Geothermal Reservoir Rocks at Simulated In-situ Conditions
}

\author{
H. Milsch ${ }^{1}$, A. Seibt ${ }^{2}$, and E. Spangenberg ${ }^{1}$ \\ ${ }^{1}$ GeoForschungsZentrum Potsdam, Telegrafenberg, D-14473 Potsdam, Germany, \\ milsch@gfz-potsdam.de \\ ${ }^{2}$ Boden Wasser Gesundheit GbR., Seestr. 7a, D-17033 Neubrandenburg, Germany
}

\begin{abstract}
In the course of stimulation and fluid production the chemical fluid-rock equilibrium of a geothermal reservoir may become disturbed by either temperature changes and/or an alteration of the fluid chemistry. Consequently, dissolution and precipitation reactions might be induced that result in permeability damage. In connection with the field investigations at a deep geothermal doublet, complementary laboratory based research is performed to address these effects. The reservoir is located at a depth of 4100 to $4200 \mathrm{~m}$ near Groß Schönebeck within the Northeast German Basin, $50 \mathrm{~km}$ north of Berlin, Germany. Within the reservoir horizon, an effective pressure of approximately $45 \mathrm{MPa}$ and a temperature of $150^{\circ} \mathrm{C}$ are encountered. Furthermore, the Lower Permian (Rotliegend) reservoir rock is saturated with a highly saline $\mathrm{Ca}-\mathrm{Na}-\mathrm{Cl}$ type formation fluid (TDS $\approx 255$ $\mathrm{g} / \mathrm{L})$. Under these conditions we performed two sets of long-term flow-through experiments. The pore fluid used during the first and the second experiment were a 0.1 molar $\mathrm{NaCl}$ solution and a synthetic $\mathrm{Ca}-\mathrm{Na}-\mathrm{Cl}$ type fluid with the specifications as above, respectively. The maximum run duration was 186 days. In detail, we experimentally addressed: (1) the effect of long-term flow on rock permeability in connection with possible changes in fluid chemistry and saturation; (2) the occurrence and consequences of baryte precipitation; and (3) potential precipitations related to oxygen-rich well water invasion during water-frac stimulation. In all sub-studies petrophysical experiments related to the evolution of rock permeability and electrical conductivity were complemented with microstructural investigations and a chemical fluid analysis. We also report the technical challenges encountered when corrosive fluids are used in long-term in-situ petrophysical experiments. After it was assured that experimental artifacts can be excluded, it is demonstrated that the sample permeability remained approximately constant within margins of $\pm 50 \%$ for nearly six months. Furthermore, an effect of baryte precipitation on the rock permeability was not observed. Finally, the fluid exchange procedure did not alter the rock transport properties. The results of the chemical fluid analysis are in support of these observations. In both experiments the electrical conductivity of the samples remained unchanged for a given fluid composition and constant $\mathrm{p}-\mathrm{T}$ conditions. This emphasizes its valuable complementary character in determining changes in rock transport properties during long-term flow-through experiments when the risk of experimental artifacts is high.
\end{abstract}

Key words: permeability; rock transport properties; hydrothermal fluid-rock interactions; long-term petrophysical experiments; geothermal reservoirs 


\section{Introduction}

2 The purpose of this paper is to report the outcome of long-term flow-through experiments that 3 complement the scientific efforts made by the GFZ-Potsdam on energy production from

4 geothermal reservoirs (www.gfz-potsdam.de/pb5/pb52/projects/Machbarkeit/ewelcome.html).

5 Within this framework a geothermal research doublet has been established at a site within the

6 Northeast German Basin near Groß Schönebeck, 50 km north of Berlin, Germany.

7 The production and injection horizon is situated at 4100 to $4200 \mathrm{~m}$ depth and is composed of 8 Lower Permian (Rotliegend) sandstones. The fault pattern analysis of a 3D structural model 9 indicates normal to strike slip faulting for the Lower Permian sediments. The formation pore pressure (pp) is $43.8 \mathrm{MPa}$, determined by $\mathrm{p}-\mathrm{T} \operatorname{logs}$ at stationary conditions of the geothermal target horizon (Legarth et al. 2005). According to the stress relation of normal faulting the

12 effective mean stress $\left(\sigma_{\text {meff }}\right)$ was calculated as $42.9 \mathrm{MPa}$ (Blöcher et al., 2008). The temperature at this location follows a normal geothermal gradient and is approximately $150^{\circ} \mathrm{C}$. The pore fluid within the formation is of $\mathrm{Ca}-\mathrm{Na}-\mathrm{Cl}$ type with a high salinity (TDS $\approx$ $255 \mathrm{~g} / \mathrm{L})$. Furthermore and in addition to other species, it has a non-negligible degree of mineralization with respect to $\mathrm{Fe}, \mathrm{Ba}$ and $\mathrm{SO}_{4}$ with concentrations typically around 67.6 $\mathrm{mg} / \mathrm{L}, 25.5 \mathrm{mg} / \mathrm{L}$, and $51.0 \mathrm{mg} / \mathrm{L}$, respectively. A detailed description of the geological situation at this site can be found in Moeck et al. (2008).

In the course of reservoir stimulation and exploitation the local thermodynamic equilibrium of the formation is disturbed. This might induce a number of fluid-fluid- and fluid-rock interactions potentially leading to permeability damage:

(1) During reservoir stimulation by a water-frac, the formation fluid is displaced by oxygenrich well water. This possibly causes the precipitation of iron hydroxides (Seibt, 2000 and references cited therein). During the former procedure the temperature in the proximity of the injection well can be as low as $30^{\circ} \mathrm{C}$. 
(2) After passing the binary power plant cycle the cooled formation fluid might become oversaturated with respect to $\mathrm{Ba}^{2+}$ and $\mathrm{SO}_{4}{ }^{2-}$. Thermodynamic calculations (CHEMEQ) with the typical in-situ concentration range indicated a positive saturation index $(\mathrm{SI}>0)$ for temperatures below $70^{\circ} \mathrm{C}$ (J. Bartels, personal communication, 2006). As this corresponds to the approximate fluid reinjection temperature, formation damage due to baryte precipitation is potentially promoted (Kühn et al, 1997; Dunn et al., 1999).

(3) Finally, any alteration of fluid saturation with respect to the different ionic species of the rock minerals (e.g. Si) might induce dissolution-precipitation reactions within the formation in the course of fluid production (Aharonov et al., 1998; Tenthorey et al., 1998).

In contrast, an effect of clay swelling on the rock permeability (e.g. Omar, 1990) in the present case is not to be expected as the rock does not contain the relevant clay minerals. The preceding conditions and processes defined the experiments performed in this study.

Both theoretical and experimental studies with a related focus on the hydro-mechanical effect of mineral dissolution and precipitation reactions have previously been performed. They concerned primarily fluid assisted rock deformation also termed pressure solution (e.g. Rutter, 1976; De Boer et al., 1977; Sprunt and Nur, 1977; Gratier and Guiguet, 1986; Tada et al., 1987). But investigations in the context of diagenesis (Small et al., 1992; Lemée and Guéguen, 1996; Aharonov et al., 1998; Tenthorey et al., 1998), as well as fracture- (Yasuhara et al., 2006) and fault-gouge evolution (Giger et al., 2007) were also performed.

These investigations indicate that such reactions in fact can lead to a significant reduction in rock permeability by means of different grain scale mechanisms. The latter are governed by a complicated interrelationship of thermodynamic-, mechanical-, and fluid chemical parameters such as temperature, local stresses, and degree of ionic fluid saturation, respectively.

Dissolution and precipitation can occur both isolated and coupled. In connection with the present study it was previously shown (Tenthorey et al., 1998) that for low temperatures $(<$ $300^{\circ} \mathrm{C}$ ) and homogeneous rock aggregates minerals other than quartz (e.g. feldspars) need 
additionally to be present. Here, the observed decrease in permeability was induced by authigenic clay phases that rapidly became precipitated after dissolution of the constituent ionic species and respective fluid oversaturation. In contrast, fracture aperture was also shown to decrease for a pure novaculite at low- and moderate temperatures displaying in fact an underlying pure dissolution process (Yasuhara et al., 2006).

The aim of this research study was to experimentally investigate the occurrence and the effect of the particular processes (1) to (3) described above. This study was conducted under realistic conditions regarding rock- and fluid type, combinations of confining- and pore pressures, flow-rates as well as temperatures. The principal physical parameter investigated in the present study was the rock permeability. The latter was complemented by continuous measurements of the electrical sample conductivity as well as a chemical analysis of the pore fluid in regular time intervals. Finally, we decribe the technical challenges encountered when using highly saline pore fluids over experimentally extremely long periods of time.

\section{Experimental Methodology}

\subsection{Sample material and fluids}

The samples tested came from a prospective oil and gas well near Eberswalde / Germany (Eb 2/76). They were chosen for their mineralogical similarity with the aquifer rocks at the close by Groß Schönebeck site where no coring was performed. The specimens are Lower Permian (Rotliegend) sandstones of the Havel subgroup originating from a depth of approximately $4150 \mathrm{~m}$.

Figure 1a shows an optical micrograph of the starting material (crossed nicols). The rock is an arcosic litharenite and consists mainly of quartz ( 80 vol\%). Quartz cement prevails (Figure 1b). The quartz grains are often surrounded by iron (III) oxide-rims responsible for the reddish colour of this type of sandstone. Carbonatic and albitic cements are rarely found. The average quartz grain size is $150 \mu \mathrm{m}$. The feldspar content is less 10 vol\%. K-feldspar 
sometimes partly albitised is predominant. Rock fragments are contained by less than $10 \mathrm{vol} \%$ and are mainly of volcanic origin. Sometimes an ophitic texture can be found. Accessory minerals are plagioclase, microcline and mica. Illite (Figure 1c) and chlorite are the dominant clays.

For the experiments smaller cores were taken parallel to the bedding. Subsequently, surface grinding was performed to obtain samples with a cylindrical shape having a diameter of 30 $\mathrm{mm}$ and a length of $40 \mathrm{~mm}$ (Figure 2). Two specimens labeled ebe05-3 and ebe05-4 were tested.

\section{Figure 1a, Figure 1b, Figure 1c, Figure 2}

The fluids used were a 0.1 molar $\mathrm{NaCl}$ solution (sample ebe05-3) and a synthetic $\mathrm{Ca}-\mathrm{Na}-\mathrm{Cl}$ type formation fluid (sample ebe05-4). The latter aimed at simulating the in-situ fluid of the Groß Schönebeck deep geothermal system (Giese et al., 2002) at this stage neglecting other ionic species. The fluid contains $99 \mathrm{~g} \mathrm{NaCl}$ and $206 \mathrm{~g} \mathrm{CaCl}_{2} \cdot 2 \mathrm{H}_{2} \mathrm{O}$ (both reagent grade) per liter distilled water and thus a total amount of dissolved solids (TDS) of $255 \mathrm{~g} / \mathrm{L}$.

The fluid conductivities at $25^{\circ} \mathrm{C}$ are $10.8 \mathrm{mS} / \mathrm{cm}(\mathrm{NaCl}$ solution) and $215 \mathrm{mS} / \mathrm{cm}$ (formation fluid), respectively and were measured with a hand held conductivity meter (WTW Multi 340i with TetraCon 325 conductivity probe). A thorough description of the formation fluid viscosity dependence on temperature is given in Section 3.5.

\subsection{Experimental procedure}

\subsubsection{Generalities}

The experiments were conducted under hydrostatic conditions in a recently set up HPTpermeameter. The apparatus as well as details of measurement procedures are described in our companion paper (Milsch et. al, 2007). Electrical conductivity measurements were 
104 performed in a four-electrode arrangement with a variable shunt-resistor. For this purpose

105 silver rims were painted onto the dried samples at a distance of $25 \mathrm{~mm}$ prior to immersion

106 with their respective fluids under vacuum (Figure 2). The latter procedure also served for

107 determining the starting porosity by comparing the dry and wet sample masses.

108 To reduce the risk of corrosion within the apparatus the synthetic formation fluid was flushed

109 with nitrogen for 12 hours to minimize its oxygen content, was then filled into the evacuated

110 pore pressure system, and was finally prepressurized with nitrogen to $0.2 \mathrm{MPa}$. After

111 assembly, the specimens were subjected to a confining- and pore pressure of 10 and $5 \mathrm{MPa}$

112 and a temperature of $30^{\circ} \mathrm{C}$, respectively defining the starting conditions.

113 Given a full stroke volume of $265 \mathrm{~mL}$ the active upstream pore fluid pump was refilled

114 approximately once per day with the respective fluid. The flow was unidirectional and

115 repeated pumping of the same fluid was not performed. Despite the ability of the apparatus to

116 perform a continuous fluid flow with four pumps only one upstream and one downstream

117 pump were active at the same time. The two others were kept on hold and they took over 118 when servicing of the former ones had become necessary. Particularly, this was the case when 119 at a given point leakage occurred due to pump seal damage as a consequence of salt 120 crystallization on the pump cylinder walls.

\subsubsection{Long-term experiment with 0.1 molar $\mathrm{NaCl}$ solution}

123 The long-term flow-through experiment with sample ebe05-3 was conducted over 45 days. A 124 continuous flow-rate of $0.1 \mathrm{~mL} / \mathrm{min}$ was applied. After confining pressure increase to $50 \mathrm{MPa}$ 125 the temperature was maintained at $30^{\circ} \mathrm{C}$ for two days and was then increased to $150^{\circ} \mathrm{C}$ for the 126 remainder of the experiment. The confining- and pore pressure were kept constant at 50 and 5

$127 \mathrm{MPa}$, respectively. 
128 For this sample SEM microstructural analysis including EDX (Energy Dispersive X-ray)

129 element mapping for $\mathrm{Si}, \mathrm{Al}, \mathrm{Fe}, \mathrm{K}, \mathrm{Ca}$, and $\mathrm{S}$ has been performed after the experiment (Zeiss

130 DSM 962 with Noran/Tracor Voyager 2.6).

\subsubsection{Long-term experiment with synthetic formation fluid}

133 The long-term flow-through experiment with sample ebe 05-4 had a total duration of 186 days.

134 The flow-rate was $0.1 \mathrm{~mL} / \mathrm{min}$ and the test was performed at a constant confining- and pore 135 pressure of 50 and $5 \mathrm{MPa}$, respectively. After confining pressure increase to $50 \mathrm{MPa}$ the 136 temperature was maintained at $30^{\circ} \mathrm{C}$ for three days and was then increased to $150^{\circ} \mathrm{C}$. After 30 137 and 83 days the flow was stopped and the sample was maintained at stable p-T conditions for 13845 and 81 days respectively. After these hold periods flow was resumed for approximately 7 139 days each.

\subsubsection{Fluid exchanges}

142 Subsequent to this first experimental stage with sample ebe05-4 the fluid was enriched with

143 progressively increased concentrations of $\mathrm{Ba}^{2+}$ and $\mathrm{SO}_{4}{ }^{2-}$ ions by adding specific amounts of 1440.1 molar $\mathrm{BaCl}_{2}$ and $\mathrm{Na}_{2} \mathrm{SO}_{4}$ solutions to the synthetic formation fluid.

145 Three different concentrations $\mathrm{n}\left(\mathrm{Ba}^{2+}\right): \mathrm{n}\left(\mathrm{SO}_{4}{ }^{2-}\right)[\mathrm{n}$ in $\mathrm{mM} / \mathrm{L}]$ were tested: (1) 0.19:0.19; (2) 146 0.19:0.57, and (3) 0.38:1.14. This covers the in-situ $\mathrm{Ba}^{2+}$ concentrations and $\mathrm{n}\left(\mathrm{Ba}^{2+}\right): \mathrm{n}\left(\mathrm{SO}_{4}{ }^{2-}\right)$

147 ratios of the Groß Schönebeck formation fluid which are in the range of 0.19 to $0.44 \mathrm{mM} / \mathrm{L}$ 148 and 1:1 to 1:3, respectively. This flow-through test had a duration of 7 days and was 149 performed at a temperature of $60^{\circ} \mathrm{C}$.

150 The fluid was then exchanged at $150^{\circ} \mathrm{C}$ against tap water acidified to $\mathrm{pH} 5$ with acetic acid and 151 the temperature was then, again, decreased to $60^{\circ} \mathrm{C}$ and then further to $30^{\circ} \mathrm{C}$. The flow with 152 tap water was maintained for 5 days. At the end of this experimental stage the tap water was 
153 finally exchanged against the original synthetic formation fluid and the temperature was 154 increased to $150^{\circ} \mathrm{C}$ to establish the starting conditions for comparison.

\subsubsection{Chemical fluid analysis (sample ebe05-4)}

157 For sample ebe $05-4$ the total amount of fluid that had transversed the sample during 60 days

158 of flow was 8.6 L. During both stages of this experiment a total of 30 fluid samples were 159 taken, generally one every second day during times of flow. The samples contained 160 approximately $150 \mathrm{~mL}$ of fluid each. Immediately after release the fluid $\mathrm{pH}$ and redox 161 potential Eh were measured at ambient p-T conditions (WTW Multi 340i with Mettler-Toledo 162 probes InLab $412(\mathrm{pH})$ and InLab $501(\mathrm{Eh}))$.

163 The fluid samples were then chemically analysed for cation and anion concentrations of Fe,

$164 \mathrm{Mn}, \mathrm{Al}, \mathrm{Zn}, \mathrm{Cu}, \mathrm{Pb}, \mathrm{K}, \mathrm{Si}, \mathrm{Ba}$, and $\mathrm{SO}_{4}$, respectively. Besides for $\mathrm{Fe}$ and $\mathrm{Mn}$ which were analysed photometrically chemical analysis was performed by either GF-AAS (Graphite

166 Furnance Atomic Absorption Spectrometry; $\mathrm{Al}, \mathrm{Zn}, \mathrm{Cu}, \mathrm{Pb}$ ) or by ICP-MS (Inductively 167 Coupled Plasma Mass Spectrometry; K, Si, Ba, and $\mathrm{SO}_{4}$ through S) at VKTA Rossendorf e.V. 168 Here, the detectable minimum concentrations, taking dilution into account, were $50 \mu \mathrm{g} / \mathrm{L}$ (Al, $169 \mathrm{Zn}), 10 \mu \mathrm{g} / \mathrm{L}(\mathrm{Cu}, \mathrm{Pb}, \mathrm{K}), 60 \mu \mathrm{g} / \mathrm{L}(\mathrm{Si}), 5 \mu \mathrm{g} / \mathrm{L}(\mathrm{Ba})$, and $1500 \mu \mathrm{g} / \mathrm{L}\left(\mathrm{SO}_{4}\right)$, respectively. For 170 this sample no post-experimental analysis of the microstructure was possible due to an O-ring 171 failure upon depressurization.

\subsubsection{Procedural overview}

174 Table I summarizes the sample properties at starting conditions and after the confining 175 pressure increase to $50 \mathrm{MPa}$, the porosity being measured at ambient pressure as described 176 above. This table emphasizes the significant effect of an effective pressure increase on both 177 transport properties. Effective pressure is meant as the difference between confining- and pore 178 pressure according to Terzaghi’s Principle (Terzaghi, 1923). 
179 The flow chart in Table II summarizes the procedures of the experiments for both samples tested.

Table I, Table II

\section{Experimental results}

185 3.1 Long-term experiment with 0.1 molar $\mathrm{NaCl}$ solution

186 The measured permeability and electrical conductivity are shown in Figures 3 and 4, 187 respectively as a function of time. The increase in electrical conductivity after two days is due 188 to the temperature increase from 30 to $150^{\circ} \mathrm{C}$. After four days the permeability started to 189 decrease from $0.33 \cdot 10^{-15} \mathrm{~m}^{2}$ to a minimum of $1.0 \cdot 10^{-17} \mathrm{~m}^{2}$. This decrease was interrupted

190 by short permeability jumps back towards its initial value. As the electrical conductivity 191 remained unchanged it was supposed that some kind of clogging had occurred at the upstream

192 side of the sample as both parameters are related at least qualitatively (Table I and e. g. 193 Martys and Garboczi, 1992).

194 The sample was then flushed with distilled water after 28 days leading to both the marked

195 decrease in electrical conductivity and the dramatic increase in permeability to approximately $19620 \%$ below its original value. Flow with the original fluid was then resumed. For the 197 remainder of the experiment the permeability continued to decrease by $40 \%$ but this time 198 slower and more or less steadily. In contrast, the electrical conductivity showed a minor 199 increase by approximately $5 \%$. At the end of the experiment between 43 and 45 days the 200 changes in both transport properties are induced by a decrease in confining pressure from 50 201 to $10 \mathrm{MPa}$ and a decrease in temperature from 150 to $40^{\circ} \mathrm{C}$, respectively after which the 202 measurement has been stopped. The trend in electrical conductivity is plausible and 203 physically connected to the changes in both parameters whereas the permeability appears 
unrelated. In fact, the upstream side of the dismantled sample showed a brownish mud like cover that very likely consisted of iron hydroxide.

\section{Figure 3, Figure 4}

3.2 Long-term experiment with synthetic formation fluid

210 The iron hydroxide originated from one single corrosive spot within the pore pressure system 211 at the thread of one of the reservoir tanks. To avoid further corrosion the synthetic formation 212 fluid and the pore pressure system were preconditioned as described in Section 2.2.1.

213 The evolution of both permeability and electrical conductivity during the first stage of this 214 experiment is shown in Figures 5, 6a, and 6b, respectively as a function of time. The decrease 215 of both transport properties after start from $4.9 \cdot 10^{-15}$ to $2.0 \cdot 10^{-15} \mathrm{~m}^{2}$ and from 5.0 to 3.8 $\mathrm{mS} / \mathrm{cm}$, respectively is due to a confining pressure increase from 10 to $50 \mathrm{MPa}$. The conductivity increase from 3.8 to approximately $11.0 \mathrm{mS} / \mathrm{cm}$ after four days from start is due to a temperature increase from 30 to $150^{\circ} \mathrm{C}$.

219 For the next 26 days the sample was continuously flown through. Within experimental errors 220 (e.g. a time dependent minor leak of the upstream pump) the permeability remained constant at $2.2 \pm 0.8 \cdot 10^{-15} \mathrm{~m}^{2}$. The two longer hold phases were introduced for comparison by allowing a chemical equilibration of the fluid with the rock. Additionally, they gave the opportunity to service the pore fluid pumps in regular time intervals. Flow was resumed after

22476 days from start. Compared to the situation before, the permeability had decreased by 225 approximately $50 \%$ to $0.9 \pm 0.1 \cdot 10^{-15} \mathrm{~m}^{2}$. In contrast, it remained nearly constant for the remainder of the experiment.

227 By the use of a highly saline fluid the electrical conductivity showed a substantial scatter 228 (Figure 6a). Interestingly, this noise was reversibly not observed when the temperature was 229 below approximately $100^{\circ} \mathrm{C}$. Furthermore, it showed that the signal sharply alternated 
230 between an upper and a lower level of $10 \pm 1.0 \mathrm{mS} / \mathrm{cm}$ during the second and third flow

231 phase. An abrupt switching of the conductivity value also becomes evident when the signal is

232 time averaged in 24 hour intervals (Figure $6 \mathrm{~b}$ ) compared to a normal sampling rate of 2 per

233 minute. This figure finally demonstrates that the electrical conductivity remains unaltered in

234 the course of the experiment at stable $\mathrm{p}$-T conditions within margins of approximately \pm 10 $235 \%$.

Figure 5, Figure 6a, Figure $6 b$

\subsection{Fluid exchanges}

240 The Figures 7, 8, and 9 show the temperature, permeability, and electrical conductivity, 241 respectively as a function of time in the course of the second stage of the experiment with 242 sample ebe05-4.

243 The lowest concentration of $\mathrm{Ba}^{2+}$ and $\mathrm{SO}_{4}{ }^{2-}$ ions was added to the pure formation fluid at a 244 temperature of $150^{\circ} \mathrm{C}$ and the latter was then decreased to $60^{\circ} \mathrm{C}$. For each of the three 245 different concentrations the flow was maintained for two to three days. Subsequently, this 246 fluid was exchanged against tap water at $150^{\circ} \mathrm{C}$ which then was flown through the sample at 24760,30 , and $60^{\circ} \mathrm{C}$, respectively for approximately one day at each temperature level. Finally, 248 the tap water was exchanged against the original, pure formation fluid to establish the starting 249 conditions both at $150^{\circ} \mathrm{C}$ and then at $30^{\circ} \mathrm{C}$.

250 As a result, neither a change in temperature nor the different fluid exchanges affected the 251 sample permeability which remained constant at approximately $1 \pm 0.1 \cdot 10^{-15} \mathrm{~m}^{2}$. The evolution of the sample permeability during both experimental stages with specimen ebe05-4

253 is summarized in Figure 10.

254 In Figure 9 the conductivity curve closely follows the temperature plot in Figure 7 unless the 255 fluid is tap water. Here, naturally, the electrical conductivity of the sample is close to zero 
$256(0.06 \mathrm{mS} / \mathrm{cm})$. By comparison, it is evident that the electrical conductivity - for a given 257 temperature and fluid composition - was not altered at neither stage of this fluid exchange 258 procedure. In addition, the conductivity value at $30^{\circ} \mathrm{C}$ and 16 days in Figure $9(3.6 \mathrm{mS} / \mathrm{cm})$ 259 matches the one measured more than 180 days before within $5 \%$.

260 Both measurements with the formation fluid at $150^{\circ} \mathrm{C}$ highlight the obvious sharply defined 261 conductivity band when this type of fluid is in motion at higher temperature. It can also be 262 seen that this scattering signal reversibly vanishes and reoccurs depending on the temperature 263 level.

264 Finally, it is worth to note that the full fluid exchange of the formation fluid against tap water 265 and vice versa took approximately 24 hours as evidenced by the conductivity signal. In 266 contrast, for a flow-rate of $0.1 \mathrm{~mL} / \mathrm{min}$, a sample volume of $28 \mathrm{~cm}^{3}$, and a porosity of 267 approximately $11 \%$ the former could have been accomplished within 30 minutes.

Figure 7, Figure 8, Figure 9, Figure 10

3.4 Chemical fluid analysis (sample ebe05-4)

272 The formation fluid $\mathrm{pH}$ before the onset of the experiment was 5.5 at $21.9^{\circ} \mathrm{C}$. The postexperiment formation fluid samples had $\mathrm{pH}$-values in the range of 5.1 and 6.6 at $20.0^{\circ} \mathrm{C}$ with no systematic trend. The redox potential measurements yielded inconsistent results and will therefore not be discussed.

276 Fe and Mn, both measured photometrically, yielded concentrations of $1.72 \pm 0.87 \mathrm{mg} / \mathrm{L}$ and $277 \quad 1.76 \pm 0.78 \mathrm{mg} / \mathrm{L}$, respectively. The former was the highest right at the beginning of the test 278 after the temperature had been increased to $150^{\circ} \mathrm{C}$ and slightly decreased in the course of the experiment. For the Mn concentration no systematic trend was observed. The principal results 280 of the chemical fluid analysis performed with GF-AAS and ICP-MS are listed in Table III and 281 will be discussed in Section 4.5. 
Table III

284

2853.5 Determination of the formation fluid viscosity by permeability measurements

286 As described in Milsch et al. (2007) the permeability $\mathrm{k}$ of a rock in the present case is 287 determined by a steady state method making direct use of Darcy's Law (e.g. Darcy, 1856; 288 Scheidegger, 1974; Bear, 1988):

289

$$
\mathrm{k}=\frac{\mathrm{q} \eta \Delta \mathrm{l}}{\Delta \mathrm{p}}
$$

292 where $\mathrm{q}, \eta, \Delta \mathrm{l}$ and $\Delta \mathrm{p}$ denote, in this order, the fluid volume flux (the Darcy velocity), the 293 (dynamic) fluid viscosity, the sample length and the pressure difference.

294 Thus, the permeability determination relies on the pressure difference measured over the 295 sample. For a given flow-rate, cross sectional area, sample length, and permeability the 296 pressure difference measured will depend on the fluid viscosity. As for a given fluid 297 composition and temperature the pressure difference was observed to remain unaltered the 298 unknown temperature dependence of the formation fluid viscosity can be calculated.

299 The latter is accomplished by comparing the pressure differences of both tap water and 300 formation fluid measured during temperature ramping (Figure 7). Under the assumptions 301 made above the formation fluid viscosity (at $5 \mathrm{MPa}$ ) is then given by:

$$
\eta(f f, T)=\frac{\Delta p(f f, T)}{\Delta p(t w, T)} \eta(t w, T)
$$


where $\eta(f f, T), \eta(t w, T), \Delta p(f f, T)$, and $\Delta p(t w, T)$ denote, in this order, the unknown

306 formation fluid viscosity, the viscosity of tap water assumed to be equal to that of pure water,

307 the pressure difference measured with the formation fluid, and the pressure difference

308 measured with tap water. All values refer to an individual temperature T.

309 In Figure 11 both pressure differences are shown as a function of temperature. For the

310 formation fluid the scatter of the measured values above $60^{\circ} \mathrm{C}$ is due to a minor leak of the

311 upstream pump. For the viscosity calculation according to Equation (2) averaged pressure

312 difference values were used. The temperature dependence of the viscosity of pure water at 5

313 MPa fluid pressure was calculated with the NIST program REFPROP.

314 Figure 12 shows both viscosity-temperature dependences so derived. All permeability values

315 presented in this paper were calculated according to the fluid-temperature conditions referring

316 to one of the two graphs. The formation fluid viscosity was also directly measured at $20^{\circ} \mathrm{C}$

317 and ambient pressure with a Höppler-viscosimeter. The value obtained was $1.72 \pm 0.05 \mathrm{mPa} \mathrm{s}$

318 which is in excellent agreement with the one estimated by extrapolating the respective graph

319 in Figure 12 to $20^{\circ} \mathrm{C}$.

Figure 11, Figure 12

\section{Discussion}

\subsection{Experimental aspects}

325 Technically, it has been shown that flow-though experiments of significant length (6 months)

326 at elevated p-T conditions are feasible. However, two principal difficulties in connection with the use of brines have been encountered. Despite a thorough material selection throughout the apparatus corrosion could not be totally avoided. As a result, an artifactic permeability decrease was observed during the first of two tests that was related to rust deposit on the upstream side of the sample. In the subsequent experiment this problem was successfully 
331 circumvented by minimizing the oxygen content within the pore pressure system through $\mathrm{N}_{2}$ -

332 flushing of the pore fluid.

333 In contrast, high salt contents of the fluid are a persistent challenge for the (dynamic) pore

334 fluid pump seals. The deposit of salt on the pump cylinder walls favors leakage. Regular 335 servicing of the pumps thus becomes necessary. The use of two active pumps and two pumps 336 on hold were proven to allow an uninterrupted fluid flow.

337 In this context it was shown that, despite generally different microstructural scale 338 dependences, complementary electrical conductivity measurements are valuable for 339 separating true from artifactic permeability changes. In addition, the electrical conductivity 340 and thus potentially evolving rock transport properties are also monitored when the fluid is 341 stationary.

4.2 Determination of the formation fluid viscosity by permeability measurements

344 We presented a method for deriving an unknown fluid viscosity and its temperature 345 dependence through permeability measurements. The measurement relies on the applicability 346 of Darcy's Law and requires a second fluid with known properties for comparison. Despite 347 the exploratory character of the method within the present study the viscosity so determined 348 was in excellent agreement with an independent measurement performed at $20^{\circ} \mathrm{C}$. The 349 technique has the advantage that no secondary experimental setup is required as the 350 measurement is performed directly with the sample to be investigated regarding its 351 permeability. The method can yield accurate results when it is ensured that no leakage occurs 352 and that the permeability in fact remains unaltered during fluid exchange. Precision in the 353 present case is favored by the excellent flow stability, pressure resolution, and temperature 354 stability provided by the apparatus. 
358 Based on the measurements performed it is concluded that during neither long-term experiment with an isochemical fluid composition any real and significant alteration of the 360 transport properties had occurred.

361 For the test with sample ebe05-3 this is supported by the fact that the permeability increases

362 dramatically towards its initial value once the fluid breaks through the rust cover at the 363 upstream side of the sample when the pressure gradient becomes high enough.

364 For the experiment with sample ebe05-4 this conclusion is directly supported by the 365 permeability measurements themselves. During the three periods of flow at stage 1 the 366 permeability remains constant within an upper and lower limit of approximately $3 \cdot 10^{-15} \mathrm{~m}^{2}$ 367 and $1 \cdot 10^{-15} \mathrm{~m}^{2}$, respectively. The permeability offset after the first hold is then interpreted to 368 be due to residual rust within the pore fluid system that has been deposited on the upstream 369 side of the sample after flow was resumed. In connection with the constancy of the sample 370 permeability for the remainder of this stage of the experiment we suggest that other processes 371 like fines migration, clay break-up and/or mineral precipitation are negligible with respect to 372 their effect on rock permeability.

373 Also during stage 2 no further change in sample permeability was observed. For baryte 374 precipitation this is evidently due to an insufficient $\mathrm{Ba}^{2+}$ and $\mathrm{SO}_{4}{ }^{2-}$ concentration. In addition, 375 precipitation experiments (A. Seibt; unpublished data) indicate that baryte nucleation is 376 significantly retarded when the fluid is in motion. For the fluid exchange against tap water 377 this indicates that an effect on the rock transport properties is only to be expected when the 378 replaced formation fluid contains a significant amount of ionic species to be oxidized (e. $\mathrm{g}$. $379 \mathrm{Fe}^{2+}$ ). 
384 The post-experimental microstructure of sample ebe05-3 showed no obvious departure from 385 the one investigated before start. Particularly, no significant infiltration of corrosion related 386 rust into the specimen had occurred as evidenced by both optical- and SE-microscopy.

387 Figure 13 shows an EDX element map taken for $\mathrm{Si}, \mathrm{Al}$, and Fe on a broken part of the sample 388 oriented perpendicular to the flow direction and taken at a distance of approximately $5 \mathrm{~mm}$ 389 from the upstream side of the specimen. Fe is only present as traces mainly related to smaller 390 amounts of iron (III) oxide preserved on the quartz grains. Si dominates due to the high quartz 391 content of the sample. Al is related to both K-feldspar and clay minerals (mainly illite and 392 chlorite). A minor K-peak observed in the EDX-spectrum emanated from the former mineral.

$393 \mathrm{Ca}$ and $\mathrm{S}$ were not detected indicating the absence of carbonatic cement and anhydrite within 394 the resolution limits.

395 Although the observed permeability decrease here was artifactic these results indicate that an 396 entire sample can become impermeable in the direction of flow when relevant amounts of 397 precipitates induce pore-clogging even with no significant spatial extent in terms of 398 infiltration depth.

Figure 13

4.5 Chemical fluid analysis (sample ebe05-4)

403 The results of the chemical analysis indicate that ionic species of $\mathrm{K}, \mathrm{Cu}, \mathrm{Zn}$ and $\mathrm{Pb}$ that have 404 been residually preserved within the sample after initial coring become easily dissolved and 405 flushed-out after flow has been started. No dissolution of Al was observed despite the 406 presence of K-feldspar as well as illite and chlorite as the principal clay minerals within the 407 samples. 
Si maintained an approximately constant (equilibrium) concentration of $30 \mathrm{ppm}$ (stage 1)

409 regardless of the flow situation. The former appears to be affected by the presence of $\mathrm{Ba}^{2+}$

410 and/or $\mathrm{SO}_{4}{ }^{2-}$ ions when the latter were introduced artificially (stage 2). In their experiments

411 Tenthorey et al. (1998) observed a four times higher Si equilibrium concentration in pure

412 water at a comparable temperature. Besides significant differences in fluid composition this

413 might be due to the fact that their fluid volume was limited $(6 \mathrm{~mL})$ and was cycled back and

414 forth through the sample potentially becoming more enriched in $\mathrm{Si}$ in terms of a true

415 equilibrium concentration.

416 An approximately constant $\mathrm{n}\left(\mathrm{Ba}^{2+}\right): \mathrm{n}\left(\mathrm{SO}_{4}{ }^{2-}\right)$ ratio of $1: 2.2 \pm 10 \%$ was observed during stage

4171 and thus prior to the enrichment of the formation fluid with these species. This indicates the

418 preservation of baryte precipitates after initial core recovery or the presence of smaller

419 amounts of baryte cement. Consequently, no effect of precipitation was observed during stage

4202 for a molar ratio of 1:1. Despite a progressive relative depletion in $\mathrm{Ba}^{2+}$ ions (fluid sample

421 21), the $\mathrm{SO}_{4}{ }^{2-}$ concentration measured indicates that barite precipitation can also be excluded

422 for the lowest $\mathrm{n}\left(\mathrm{Ba}^{2+}\right): \mathrm{n}\left(\mathrm{SO}_{4}{ }^{2-}\right)$ ratios investigated in the present study.

423 In summary, these results suggest that dissolution of various species including quartz is viable

424 and could even result in an increase in sample permeability. In contrast, an effect of potential 425 precipitation reactions on the rock transport properties appears negligible under the conditions 426 investigated.

428 5. Conclusions

429 We conducted long-term flow-through experiments to investigate risks of permeability 430 damage related to fluid-rock interactions and specifically to dissolution and precipitation 431 reactions. Besides experiments performed with a nominally isochemical fluid composition, 432 potential effects of both baryte precipitation and well water injection during reservoir 433 stimulation were investigated. The effective pressure- and temperature conditions applied and 
434 the rock- and fluid types chosen aimed at simulating the setting within a geothermal research

435 doublet established at a site within the Northeast German Basin.

436 During a maximum of six months of flow no significant change in permeability in neither

437 direction was observed. Additionally, no negative effect of baryte precipitation or the

438 exchange of the formation fluid against oxygen-rich water was encountered.

439 Despite significant differences in experimental strategy some of the observations made are in 440 agreement with the results obtained by Tenthorey et al. (1998). At moderate temperatures, 441 samples rich in quartz will show no permeability damage, unless the composition of an 442 externally introduced fluid allows authigenic mineral precipitation. Even with high feldspar 443 contents their experiments demonstrated that the observed permeability decrease stopped only 444 after a few days as a result of their closed fluid-rock system reaching equilibrium.

445 In the present study the fluid has been continuously replaced as is the case within the reservoir 446 during production. Further investigations should therefore address more systematically the 447 effect of rock feldspar content, fluid composition, and flow-rate for both open and closed fluid 448 systems in comparison.

449 Finally, a comparative study should be undertaken on both diagenetically consolidated rock 450 samples and specimens made from compacted mineral sands having a similar composition. 451 Here, differences in reactive surface area and -energy could significantly affect the style and 452 the degree of secondary mineral precipitation potentially leading to permeability damage.

\section{Acknowledgements}

The authors thank Jörn Bartels, GTN-Neubrandenburg for constructive discussions in the course of this study and Heinz Holl, GFZ Potsdam for the petrographic interpretation of the rock microstructure. The chemical analysis of the fluid samples was perfomed by Petra Steinbach, VKTA Rossendorf e.V. Stefan Gehrmann is thanked for the preparation of the thin-sections and Helga Kemnitz as well as Juliane Herwig for their assistance with the SEM. The suggestions made by two anonymous reviewers helped to improve the manuscript. This research project was financially supported by the Federal Ministry for the Environment, 


\section{References}

Aharonov, E., Tenthorey, E., and Scholz, C. H.: Precipitation sealing and diagenesis: 2. Theoretical analysis. J. Geophys. Res. 103 (B10), 23969-23981 (1998).

Bear, J.: Dynamics of fluids in porous media. Dover Publ., Inc. Mineola, NY (1988).

Blöcher, G., Moeck, I., Milsch, H., and Zimmermann, G.: Modelling of pore pressure response due to hydraulic stimulation treatments at the geothermal research doublet EGrSk3/90 and GtGrSk4/05 in summer 2007. Proceedings, $33^{\text {rd }}$ Workshop on Geothermal Reservoir Engineering, Stanford University, Stanford, California, SGPTR-185 (2008).

Darcy, H.: Les fontaines publique de la ville de Dijon. Dalmont, Paris (1856).

De Boer, R. B., Nagtegaal, P. J. C., and Duyvis, E. M.: Pressure solution experiments on quartz sand. Geochim. Cosmochim. Acta 41, 257-264 (1977).

Dunn, K., Daniel, E., Shuler, P. J., Chen, H. J., Tang, Y., and Yen, T. F.: Mechanisms of surface precipitation and dissolution of baryte: A morphology approach. J. Colloid Interf. Sci. 214 (2), 427-437 (1999).

Giese, L., Seibt, A., Wiersberg, T., Zimmer, M., Erzinger, J., Niedermann, S., and Pekdeger, A.: Geochemie der Formationsfluide. In: Huenges, E. and Hurter, S. (eds.) In-situ Geothermielabor Groß Schönebeck: Bohrarbeiten, Bohrlochmessungen, Hydraulik, Formationsfluide, Tonminerale. Scientific Technical Report, STR02/14, GeoForschungsZentrum Potsdam, Potsdam, Germany (2002).

Giger, S. B., Tenthorey, E., Cox, S. F., and Fitz Gerald, J. D.: Permeability evolution in quartz fault gouges under hydrothermal conditions. J. Geophys. Res. 112, B07202 (2007).

Gratier, J. P. and Guiguet, R.: Experimental pressure solution-deposition on quartz grains: the crucial effect of the nature of the fluid. J. Struct. Geol. 8 (8), 845-856 (1986). 
Kühn, M., Frosch, G., Kölling, M., Kellner, T., Althaus, E., and Schulz, H. D.: Experimentelle Untersuchungen zur Barytübersättigung einer Thermalsole, Grundwasser 3, 111-117 (1997).

493

494

495

496

497

498

499

500

501

502

503

504

Legarth, B., Huenges, E., and Zimmermann, G.: Hydraulic fracturing in a sedimentary geothermal reservoir: Results and implications. Int. J. Rock Mech. Min. Sci. 42, 10281041 (2005).

Lemée, C. and Guéguen, Y.: Modelling of porosity loss during compaction and cementation of sandstones. Geology 24, 875-878 (1996).

Martys, N. S. and Garboczi, E. J.: Length scales relating the fluid permeability and electrical conductivity in random two-dimensional porous media. Phys. Rev. B 46, 6080-6090 (1992).

Milsch, H., Spangenberg, E., Kulenkampff, J., and Meyhöfer, S.: A new apparatus for longterm petrophysical investigations on geothermal reservoir rocks at simulated in-situ conditions. Transp. Porous Med., doi 10.1007/s11242-007-9186-4 (2007).

Moeck, I., Schandelmeier, H., and Holl, H.-G.: The stress regime in a Rotliegend reservoir of the Northeast German Basin. Int. J. Earth Sci., doi 10.1007/s00531-008-0316-1 (2008).

Omar, A. E.: Effect of brine composition and clay content on the permeability damage of sandstone cores. J. Petroleum Sci. Eng. 4, 245-256 (1990).

Rutter, E. H.: The kinetics of rock deformation by pressure solution. Philos. Trans. R. Soc. London, Ser. A 283, 203-219 (1976).

Scheidegger, A. E.: The physics of flow through porous media. Univ. of Toronto Press, Toronto (1974).

Seibt, A.: Welche Faktoren können die Eisen(II)-Oxigation in Formationswässern beeinflussen? In: Huenges, E. (ed.) Geothermische Energieentwicklung - geologische 
und energietechnische Ansatzpunkte. Scientific Technical Report, STR00/23, GeoForschungsZentrum Potsdam, Potsdam, Germany (2000).

517 Small, J. S., Hamilton, D. L., and Habesch, S.: Experimental simulation of clay precipitation within reservoir sandstones: 1. Techniques and examples. J. Sediment. Petrol. 62, 508519 (1992).

Sprunt, E. S. and Nur, A.: Destruction of porosity through pressure solution. Geophysics 42, 726-741 (1977).

Tada, R., Maliva, R., and Siever, R.: A new mechanism for pressure solution in porous quartzose sandstone. Geochim. Cosmochim. Acta 51, 2295-2301 (1987).

Tenthorey, E., Scholz, C. H., Aharonov, E., and Léger, A.: Precipitation sealing and diagenesis: 1. Experimental results. J. Geophys. Res. 103 (B10), 23951-23967 (1998).

Terzaghi, K.: Die Berechnung der Durchlässigkeitsziffer des Tones aus dem Verlauf der hydrodynamischen Spannungserscheinungen. Sitz. Akad. Wiss. Wien, Math. Naturwiss. K1., Abt. IIa, v. 132, 105-124 (1923). of fracture permeability through fluid-rock reaction under hydrothermal conditions. Earth Planet. Sci. Lett. 244, 186-200 (2006). 
Table I: Sample properties at starting conditions.

The pore pressure was $5 \mathrm{MPa}$ and pc denotes the confining pressure. The specific electrical conductivity is given at a temperature of $30^{\circ} \mathrm{C}$.

\begin{tabular}{cccccc}
\hline Sample Nr. & Porosity [\%] & $\begin{array}{c}\text { Permeability } \\
{\left[\mathrm{m}^{2}\right]}\end{array}$ & $\begin{array}{c}\text { Permeability } \\
{\left[\mathrm{m}^{2}\right]}\end{array}$ & $\begin{array}{c}\text { Conductivity } \\
{[\mathrm{mS} / \mathrm{cm}]}\end{array}$ & $\begin{array}{c}\text { Conductivity } \\
{[\mathrm{mS} / \mathrm{cm}]}\end{array}$ \\
\hline ebe05-3 & 12.3 & $0.45 \cdot 10^{-15}$ & $0.33 \cdot 10^{-15}$ & 0.32 & 0.26 \\
\hline ebe05-4 & 11.1 & $4.9 \cdot 10^{-15}$ & $2.0 \cdot 10^{-15}$ & 5.0 & 3.8 \\
\hline
\end{tabular}

Table II: Flow chart of the experimental procedure.

\section{Sample ebe05-3}

Sample ebe05-4

0.1 molar NaCl-fluid $\quad$ synthetic formation fluid (TDS = 255 g/L)

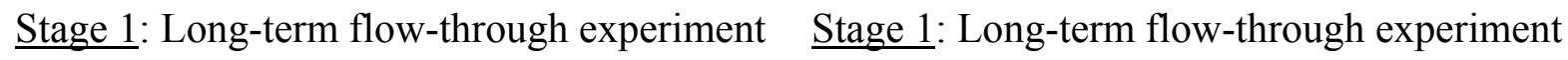

$\mathrm{T}=150^{\circ} \mathrm{C}, \mathrm{pc}=50 \mathrm{MPa}, \mathrm{pp}=5 \mathrm{MPa} \quad \mathrm{T}=150^{\circ} \mathrm{C}, \mathrm{pc}=50 \mathrm{MPa}, \mathrm{pp}=5 \mathrm{MPa}$

Measured parameters: $k, \sigma=f(t) \quad$ Measured parameters: $k, \sigma=f(t)$

Duration: 45 days, $\mathrm{Q}=0.1 \mathrm{~mL} / \mathrm{min} \quad$ Duration: 170 days, $\mathrm{Q}=0.1 \mathrm{~mL} / \mathrm{min}$

Stage 2: Fluid exchanges

$\mathrm{pc}=50 \mathrm{MPa}, \mathrm{pp}=5 \mathrm{MPa}$

Measured parameters: $\mathrm{k}, \sigma=\mathrm{f}(\mathrm{t})$

A) synthetic formation fluid + three different concentrations of $\mathrm{Ba}$ and $\mathrm{SO}_{4}$ ions

$$
\mathrm{T}=60^{\circ} \mathrm{C}
$$

B) tap water acidified to $\mathrm{pH} 5$

$$
\mathrm{T}=60 \text { and } 30^{\circ} \mathrm{C}
$$

Duration: 16 days, $\mathrm{Q}=0.1 \mathrm{~mL} / \mathrm{min}$

$\mathrm{k}$, permeability; $\sigma$, electrical conductivity; $\mathrm{t}$, time; $\mathrm{pc}$, confining pressure; $\mathrm{pp}$, pore pressure; $\mathrm{T}$, temperature; Q, flow-rate 
Table III: Results of the chemical fluid analysis (sample ebe05-4).

\begin{tabular}{|c|c|c|c|c|c|c|c|c|c|c|}
\hline $\begin{array}{c}\text { fluid } \\
\text { sample } \\
\text { number }\end{array}$ & $\begin{array}{l}\text { days } \\
\text { from } \\
\text { start }\end{array}$ & $\begin{array}{c}\mathrm{Si} \\
{[\mathrm{mg} / \mathrm{L}]}\end{array}$ & $\begin{array}{c}\mathrm{K} \\
{[\mathrm{mg} / \mathrm{L}]}\end{array}$ & $\begin{array}{c}\mathrm{Ba} \\
{[\mathrm{mg} / \mathrm{L}]}\end{array}$ & $\begin{array}{c}\mathrm{SO}_{4} \\
{[\mathrm{mg} / \mathrm{L}]}\end{array}$ & $\begin{array}{c}\mathrm{Al} \\
{[\mathrm{mg} / \mathrm{L}]}\end{array}$ & $\begin{array}{c}\mathrm{Cu} \\
{[\mathrm{mg} / \mathrm{L}]}\end{array}$ & $\begin{array}{c}\mathrm{Zn} \\
{[\mathrm{mg} / \mathrm{L}]}\end{array}$ & $\begin{array}{c}\mathrm{Pb} \\
{[\mathrm{mg} / \mathrm{L}]}\end{array}$ & fluid \\
\hline Reference & 0 & 0.39 & 6.5 & 0.1 & 11.0 & $<0.05$ & 0.102 & $<0.05$ & 0.020 & $\mathrm{ff}$ \\
\hline 3 & 5 & 32.3 & 28.4 & 39.1 & 61.5 & $<0.05$ & 1.000 & 0.216 & 1.040 & $\mathrm{ff}$ \\
\hline 5 & 7 & 23.6 & & 30.5 & 51.6 & & & & & ff \\
\hline 8 & 14 & 29.4 & & 60.3 & 88.8 & & & & & $\mathrm{ff}$ \\
\hline 10 & 19 & 26.4 & & 51.9 & 77.7 & & & & & $\mathrm{ff}$ \\
\hline $\begin{array}{c}16 \\
\text { after hold }\end{array}$ & 78 & 31.4 & 9.9 & 33.2 & 52.5 & $<0.05$ & 0.418 & $<0.05$ & 0.049 & $\mathrm{ff}$ \\
\hline $\begin{array}{c}17 \mathrm{a} \\
\text { after hold }\end{array}$ & 166 & 32.0 & 0.9 & 31.4 & 48.6 & $<0.05$ & 0.189 & $<0.05$ & 0.032 & $\mathrm{ff}$ \\
\hline 18 & 174 & 17.2 & & 21.8 & 33.9 & & & & & (1) \\
\hline 19 & 175 & 12.2 & & 29.9 & 37.8 & & & & & (1) \\
\hline 20 & 178 & 6.2 & & 28.6 & 54.3 & & & & & (2) \\
\hline 21 & 179 & 2.1 & & 31.4 & 128.0 & & & & & (3) \\
\hline 22 & 180 & 2.6 & & 25.9 & 69.6 & & & & & ff \\
\hline 23 & 181 & 1.6 & & 17.3 & 42.6 & & & & & $\mathrm{ff}$ \\
\hline
\end{tabular}

ff: pure formation fluid;

(1) $\mathrm{ff}+\mathrm{n}\left(\mathrm{Ba}^{2+}\right)=0.19 \mathrm{mM} / \mathrm{L}+\mathrm{n}\left(\mathrm{SO}_{4}{ }^{2-}\right)=0.19 \mathrm{mM} / \mathrm{L}$;

(2) $\mathrm{ff}+\mathrm{n}\left(\mathrm{Ba}^{2+}\right)=0.19 \mathrm{mM} / \mathrm{L}+\mathrm{n}\left(\mathrm{SO}_{4}{ }^{2-}\right)=0.57 \mathrm{mM} / \mathrm{L}$;

(3) $\mathrm{ff}+\mathrm{n}\left(\mathrm{Ba}^{2+}\right)=0.38 \mathrm{mM} / \mathrm{L}+\mathrm{n}\left(\mathrm{SO}_{4}{ }^{2-}\right)=1.14 \mathrm{mM} / \mathrm{L}$. 
$589 \quad$ Figure 1

(a) Optical micrograph (crossed nicols) of the starting material. The magnification is $100 x$. See text for more details on the sample microstructure. (b) SEM-image (BSE-mode) of broken sample (ebe05-3) showing quartz grains (center) and quartzitic cement (lower right).

(c) SEM-image (BSE-mode) of broken sample (ebe05-3) showing fibrous illite growing into the pore space.

Figure 2 Sample with silver paint rims at a distance of $25 \mathrm{~mm}$ for electrical conductivity measurements. The sample is $30 \mathrm{~mm}$ in diameter and $40 \mathrm{~mm}$ in length.

Figure 3 Sample ebe05-3. Permeability as a function of time. Permeability fluctuations are due to rust deposit on the upstream side of the sample. After flushing with distilled water at 28 days the permeability remained more or less constant at approximately $20 \%$ below its initial value.

Figure 4 Sample ebe05-3. Electrical conductivity as a function of time. Significant changes in electrical conductivity at stable p-T conditions ( 2 to 43 days) were not observed. This supports the conclusion of unaltered transport properties of the sample in the course of the experiment. The decrease in electrical conductivity at 28 days is due to sample flushing with distilled water.

Figure 5 Sample ebe05-4, stage 1. Permeability as a function of time. During the three periods of flow at stable p-T conditions (4 to 170 days) the permeability remained constant within margins of approximately $3 \cdot 10^{-15} \mathrm{~m}^{2}$ and $1 \cdot 10^{-15}$ 
616 Figure 6

$\mathrm{m}^{2}$, respectively. For an interpretation of the permeability offset after the first hold see Section 4.3 for more details.

(a) Sample ebe05-4, stage 1 . Electrical conductivity as a function of time. Due to the high salt content of the synthetic formation fluid the electrical conductivity signal became reversibly disturbed above temperatures of approximately $100^{\circ} \mathrm{C}$. During flow after the second and third hold the signal alternated sharply between a lower and an upper level of 9 and $11 \mathrm{mS} / \mathrm{cm}$, respectively.

(b) Sample ebe05-4, stage 1. As in (a) but the signal was time-averaged over 24 hours. Here, signal alternation becomes more apparent. In addition, the graph evidently indicates the constancy of the electrical sample conductivity within margins of $10 \pm 1.0 \mathrm{mS} / \mathrm{cm}$. In connection with the permeability measurement this supports the conclusion of unaltered sample transport properties in the course of the experiment within experimental limits.

Figure 7 Sample ebe05-4, stage 2. Temperature as a function of time during the fluid exchange procedure. During fluid exchange the formation fluid was first enriched with $\mathrm{Ba}^{2+}$ and $\mathrm{SO}_{4}{ }^{2-}$ ions and was then replaced by tap water acidified to $\mathrm{pH} 5$.

Figure 8 Sample ebe05-4, stage 2. Permeability as a function of time. Neither a change in temperature nor the different fluid exchanges affected the sample permeability which remained constant at approximately $1 \pm 0.1 \cdot 10^{-15} \mathrm{~m}^{2}$. 
Figure 9 Sample ebe05-4, stage 2. Electrical conductivity as a function of time. At stable $\mathrm{p}-\mathrm{T}$ and fluid compositional conditions the electrical sample conductivity remained constant. Note the sharply alternating signal when flow was performed with the formation fluid at $150^{\circ} \mathrm{C}$. Also note that the exchange of formation fluid against tap water and vice versa took approximately 24 hours. This is significantly longer than expected for the given flow-rate $(0.1 \mathrm{~mL} / \mathrm{min})$ and the sample porosity $(11.1 \%)$.

Figure 10 Sample ebe05-4, both stages. Summary of the permeability evolution of the sample as a function of time for comparison.

Figure 11 Sample ebe05-4. Pressure differences measured for both formation fluid and tap water during the fluid exchange procedure in stage 2 as a function of temperature. This data was used to calculate the unknown temperature dependence of the formation fluid viscosity (Figure 12) according to Equation (2) in Section 3.5.

Figure 12 Sample ebe05-4. Viscosity of both formation fluid and tap water as a function of temperature. See Section 3.5 for more details. All permeability values presented in this paper were calculated according to the fluid-temperature conditions referring to one of the two graphs.

Figure 13 Results of post-experimental EDX element mapping for $\mathrm{Si}, \mathrm{Al}$ and $\mathrm{Fe}$ (sample ebe05-3). Si prevails due to the high quartz content of the sample. Al emanates from both K-feldspar and clay minerals (mainly illite and chlorite). The Fe 
content is very low and mainly related to smaller amounts of iron (III) oxide preserved on the quartz grains. See text for more details. 


\section{Figures}

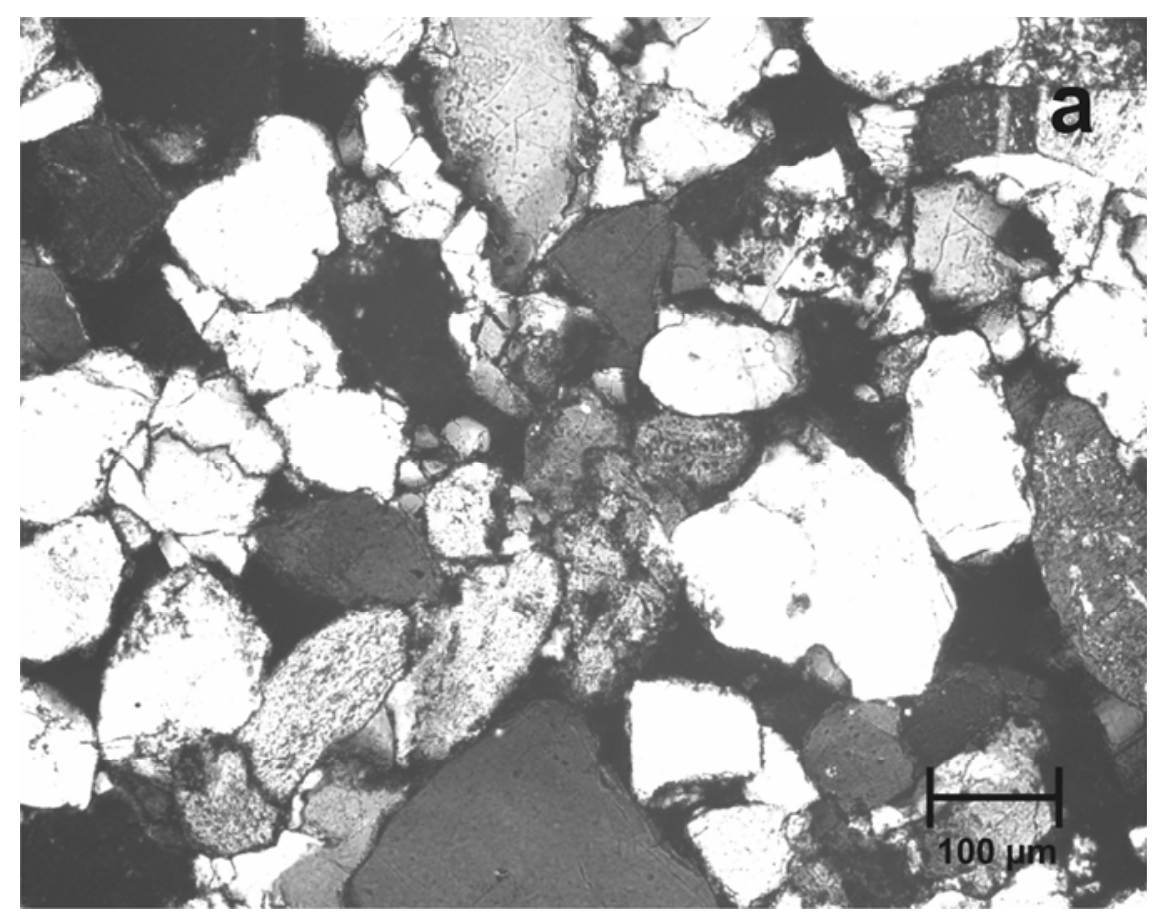

Figure 1a Optical micrograph (crossed nicols) of the starting material. The magnification is $100 x$. See text for more details on the sample microstructure. 


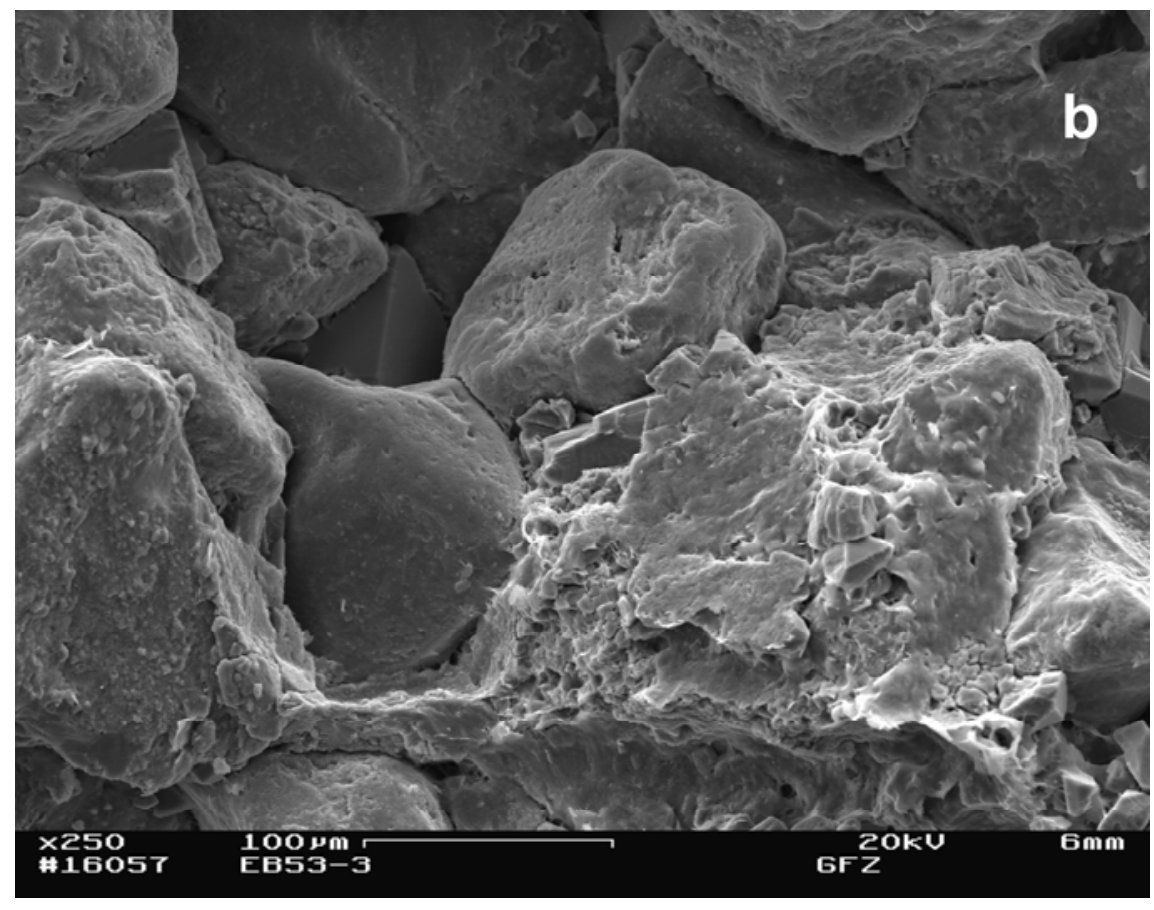

Figure 1b SEM-image (BSE-mode) of broken sample (ebe05-3) showing quartz grains (center) and quartzitic cement (lower right). 


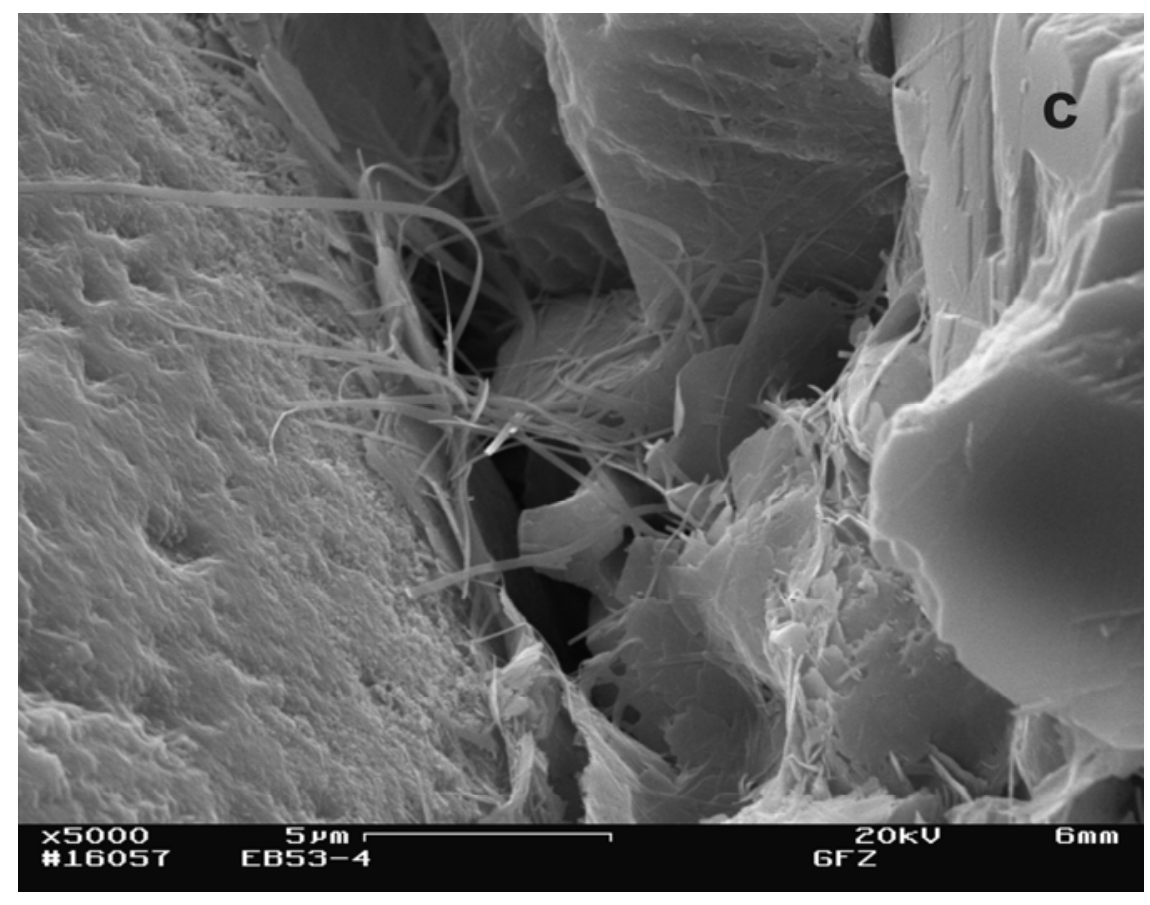

Figure 1c SEM-image (BSE-mode) of broken sample (ebe05-3) showing fibrous illite growing into the pore space. 


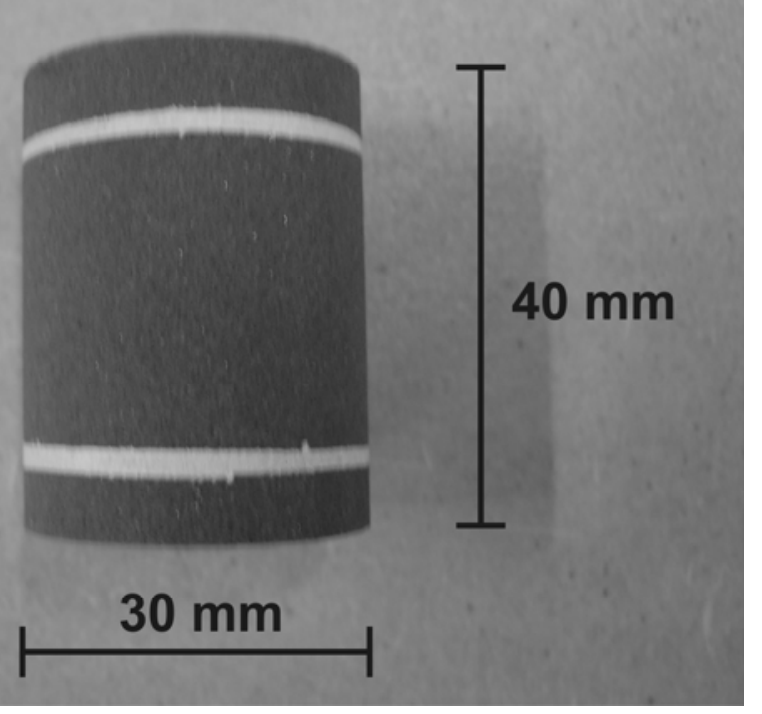

Figure 2 Sample with silver paint rims at a distance of $25 \mathrm{~mm}$ for electrical conductivity measurements. The sample is $30 \mathrm{~mm}$ in diameter and $40 \mathrm{~mm}$ in length. 
ebe 05-3 $\quad \mathrm{T}=150^{\circ} \mathrm{C}$

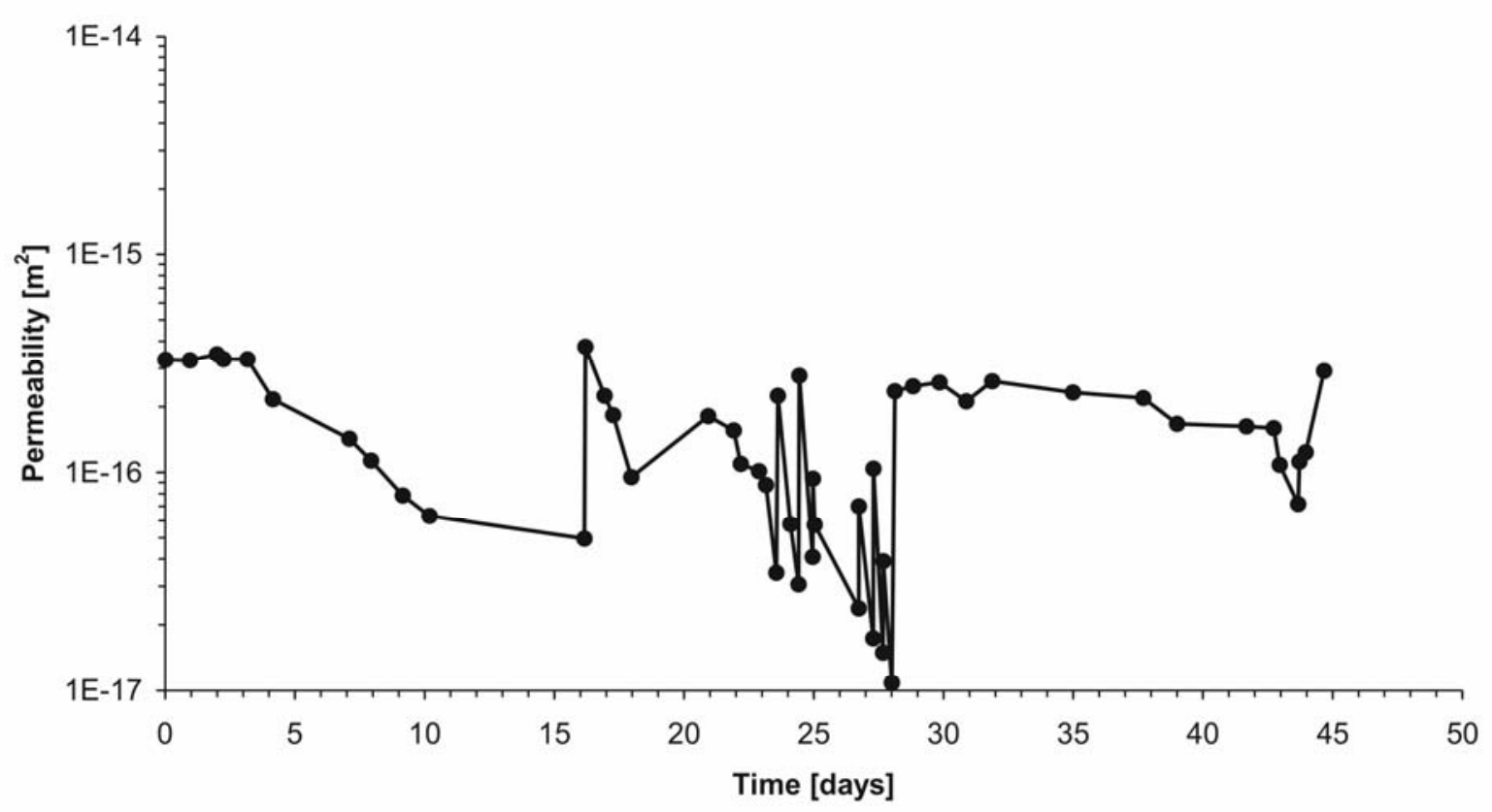

Figure 3 Sample ebe05-3. Permeability as a function of time. Permeability fluctuations are due to rust deposit on the upstream side of the sample. After flushing with distilled water at 28 days the permeability remained more or less constant at approximately $20 \%$ below its initial value. 
ebe05-3 $\mathrm{T}=150^{\circ} \mathrm{C}$

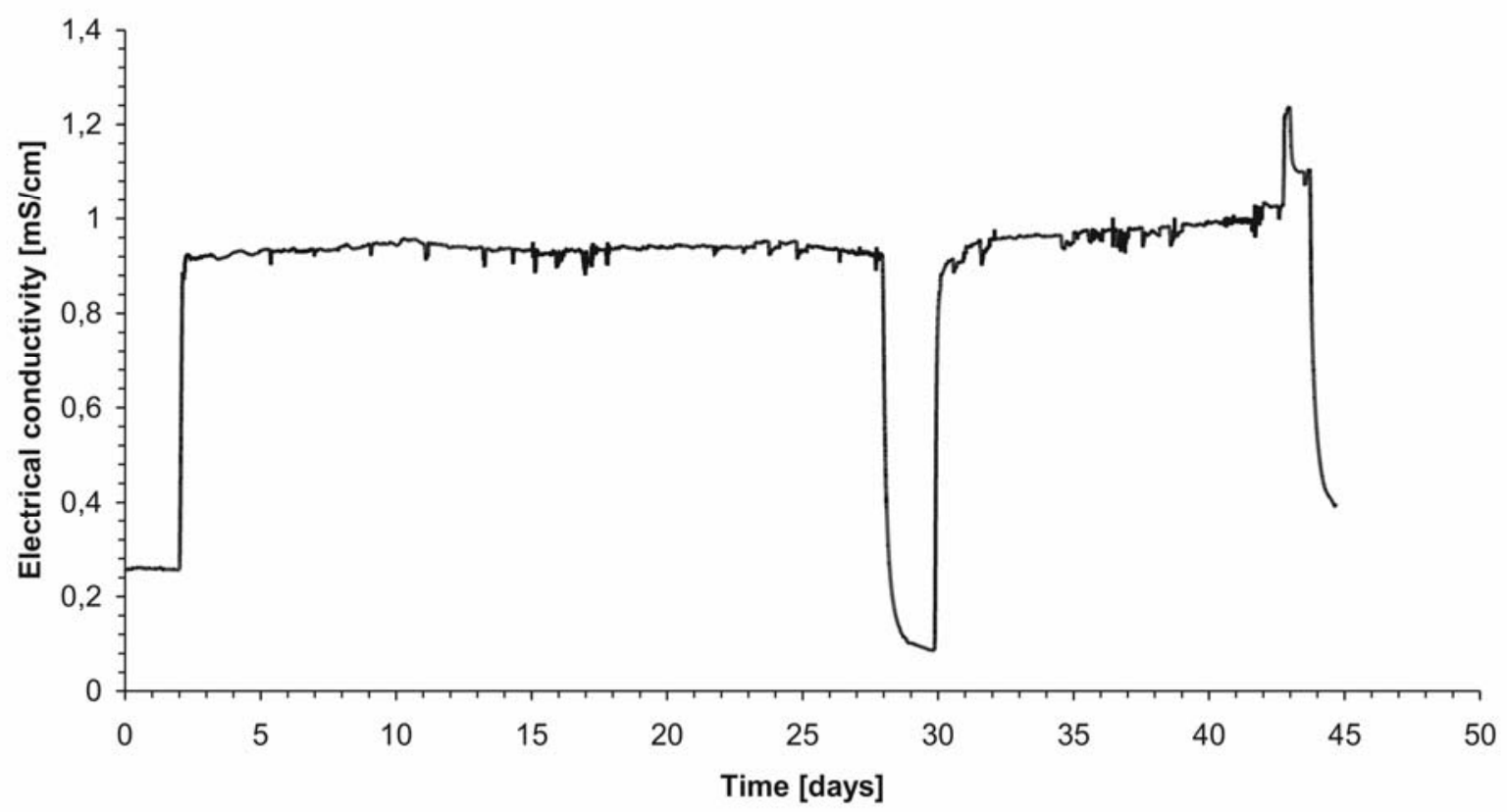

Figure 4 Sample ebe05-3. Electrical conductivity as a function of time. Significant changes in electrical conductivity at stable p-T conditions ( 2 to 43 days) were not observed. This supports the conclusion of unaltered transport properties of the sample in the course of the experiment. The decrease in electrical conductivity at 28 days is due to sample flushing with distilled water. 


\section{ebe $05-4 \quad \mathrm{~T}=150^{\circ} \mathrm{C}$ stage 1}

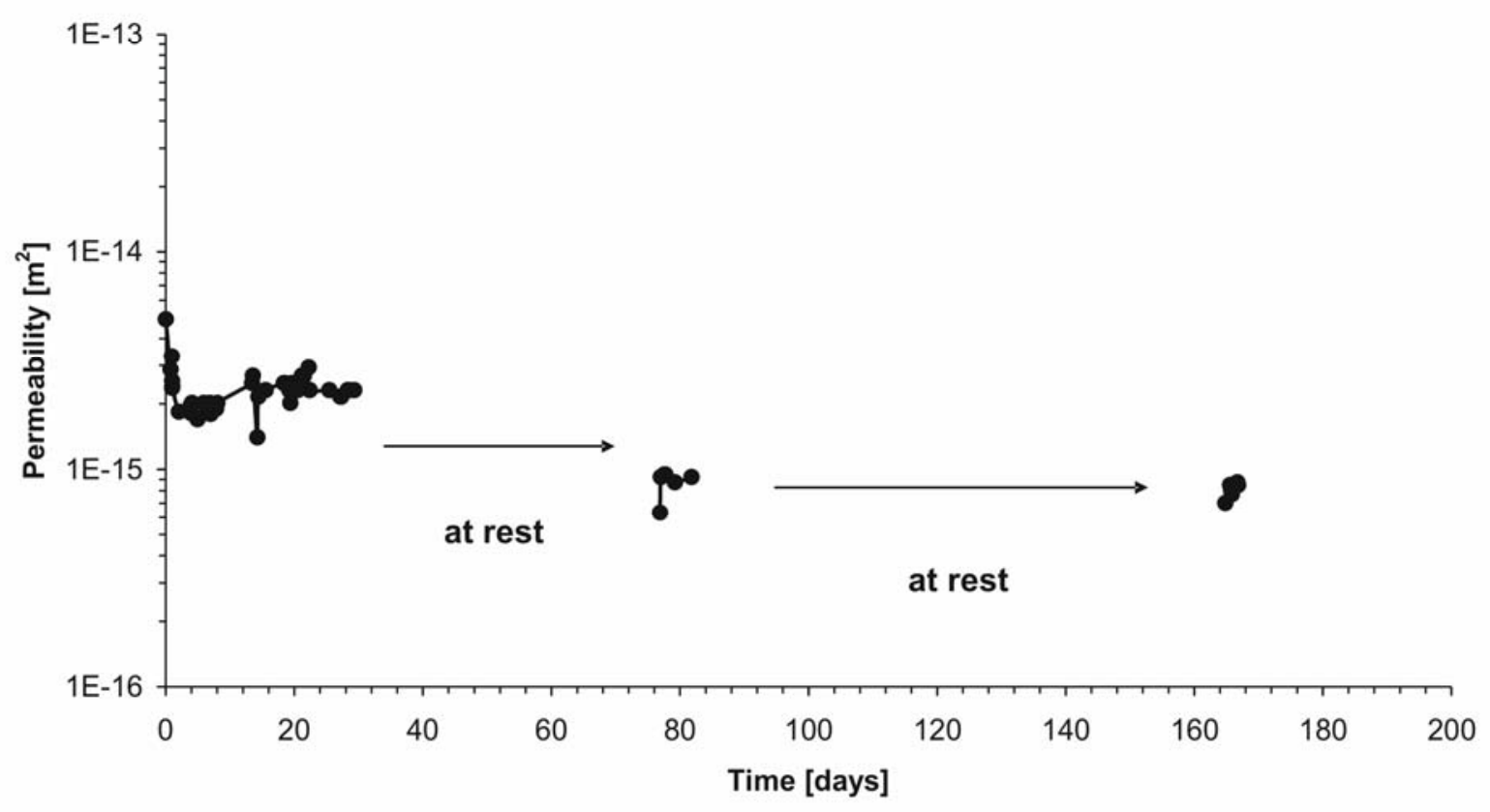

Figure 5 Sample ebe05-4, stage 1. Permeability as a function of time. During the three periods of flow at stable p-T conditions (4 to 170 days) the permeability remained constant within margins of approximately $3 \cdot 10^{-15} \mathrm{~m}^{2}$ and $1 \cdot 10^{-15}$ $\mathrm{m}^{2}$, respectively. For an interpretation of the permeability offset after the first hold see Section 4.3 for more details. 


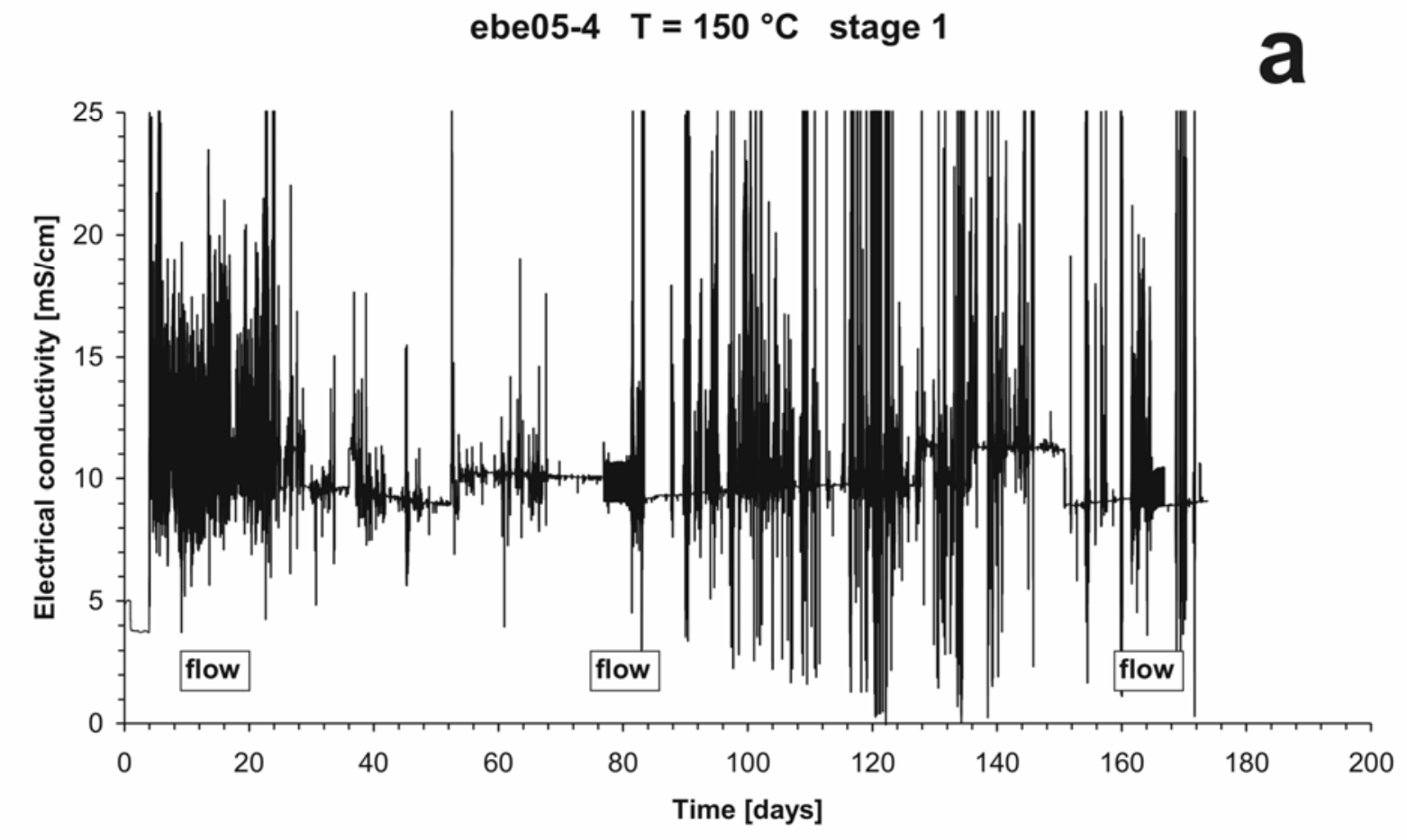

Figure 6a Sample ebe05-4, stage 1. Electrical conductivity as a function of time. Due to the high salt content of the synthetic formation fluid the electrical conductivity signal became reversibly disturbed above temperatures of approximately $100^{\circ} \mathrm{C}$. During flow after the second and third hold the signal alternated sharply between a lower and an upper level of 9 and $11 \mathrm{mS} / \mathrm{cm}$, respectively. 
ebe $05-4 \quad T=150^{\circ} \mathrm{C}$ stage 1

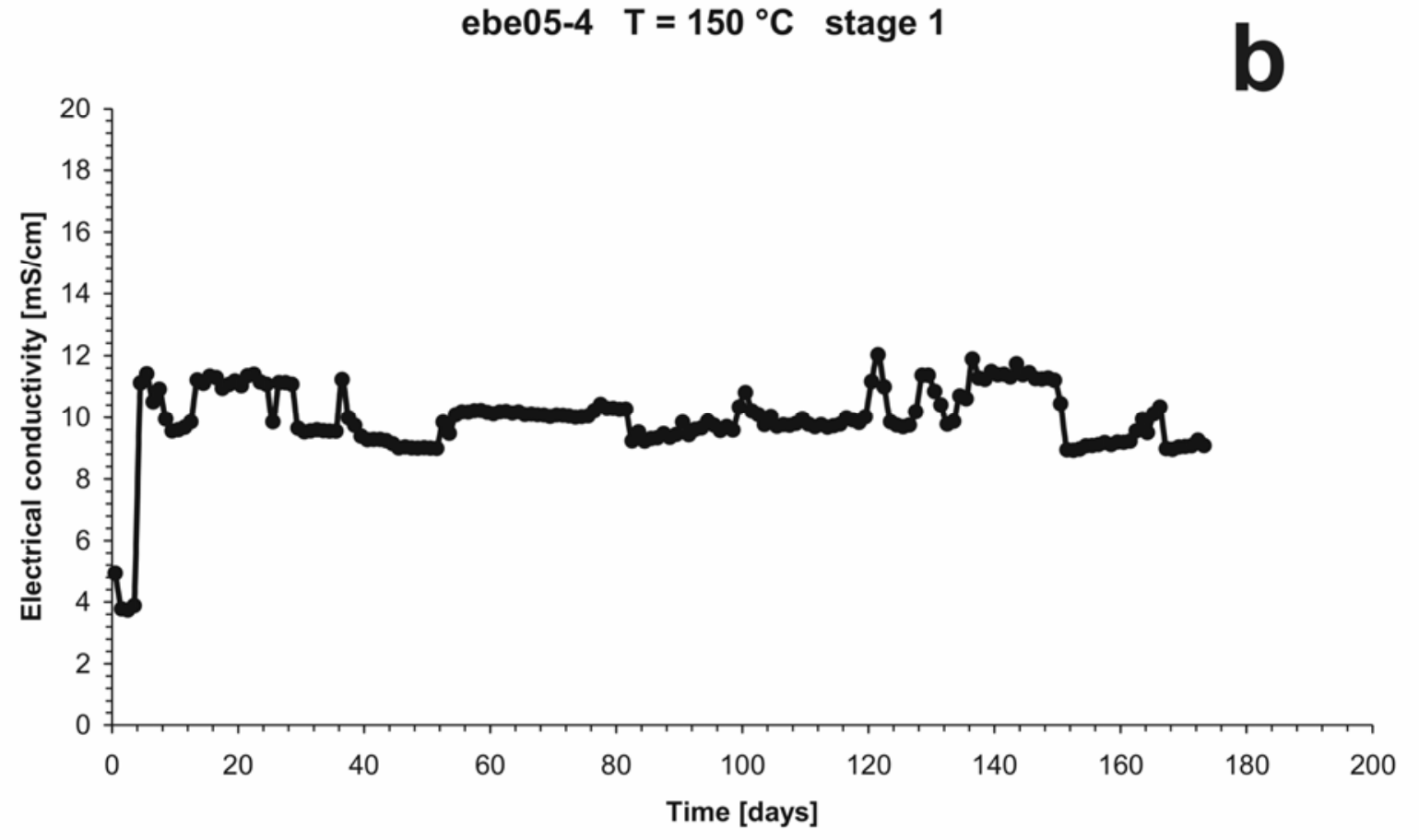

Figure $6 \mathrm{~b}$ Sample ebe05-4, stage 1. As in (a) but the signal was time-averaged over 24 hours. Here, signal alternation becomes more apparent. In addition, the graph evidently indicates the constancy of the electrical sample conductivity within margins of $10 \pm 1.0 \mathrm{mS} / \mathrm{cm}$. In connection with the permeability measurement this supports the conclusion of unaltered sample transport properties in the course of the experiment within experimental limits. 
ebe05-4 stage 2

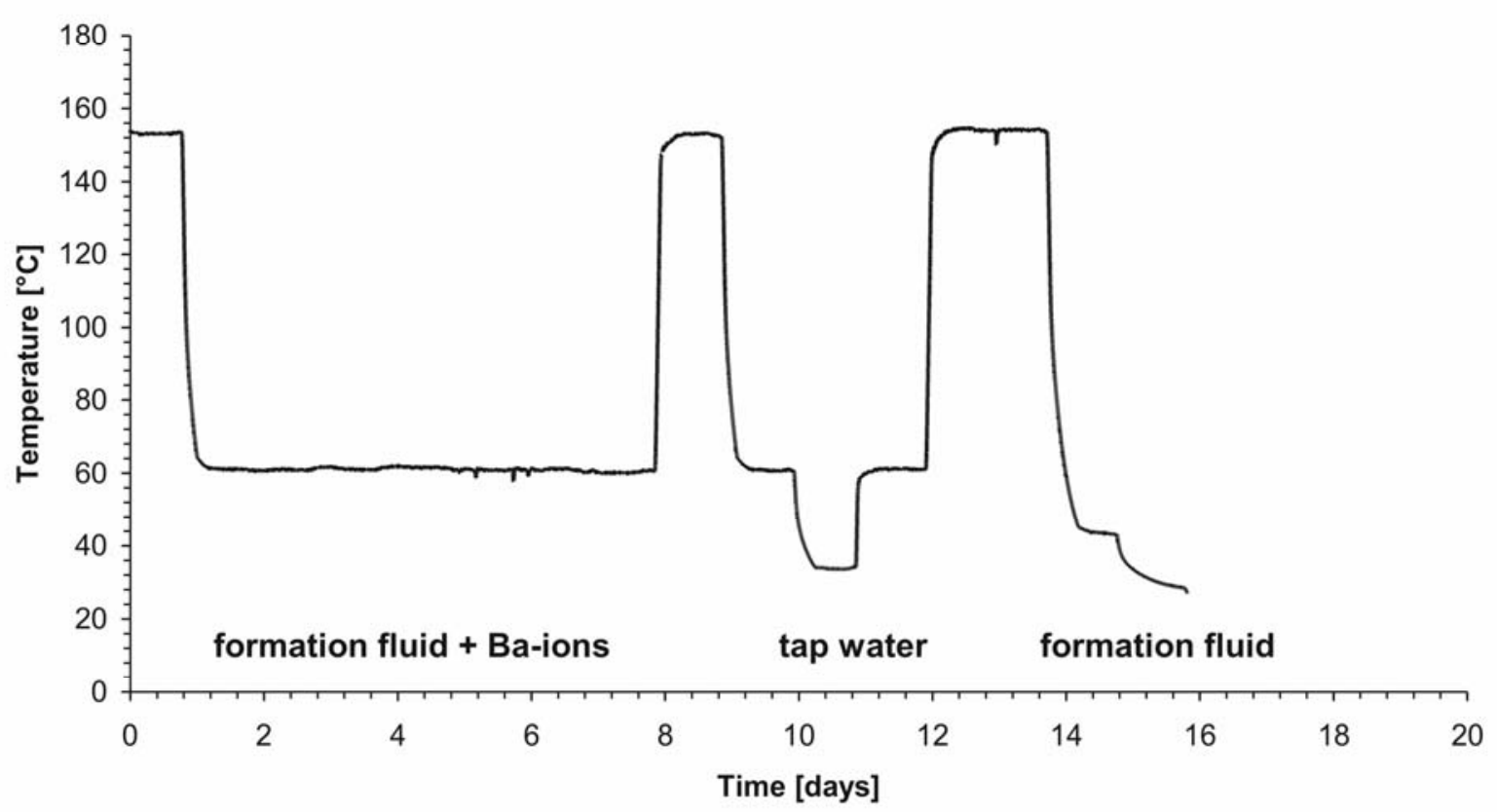

Figure 7 Sample ebe05-4, stage 2. Temperature as a function of time during the fluid exchange procedure. During fluid exchange the formation fluid was first enriched with $\mathrm{Ba}^{2+}$ and $\mathrm{SO}_{4}{ }^{2-}$ ions and was then replaced by tap water acidified to $\mathrm{pH} 5$. 
ebe 05-4 stage 2

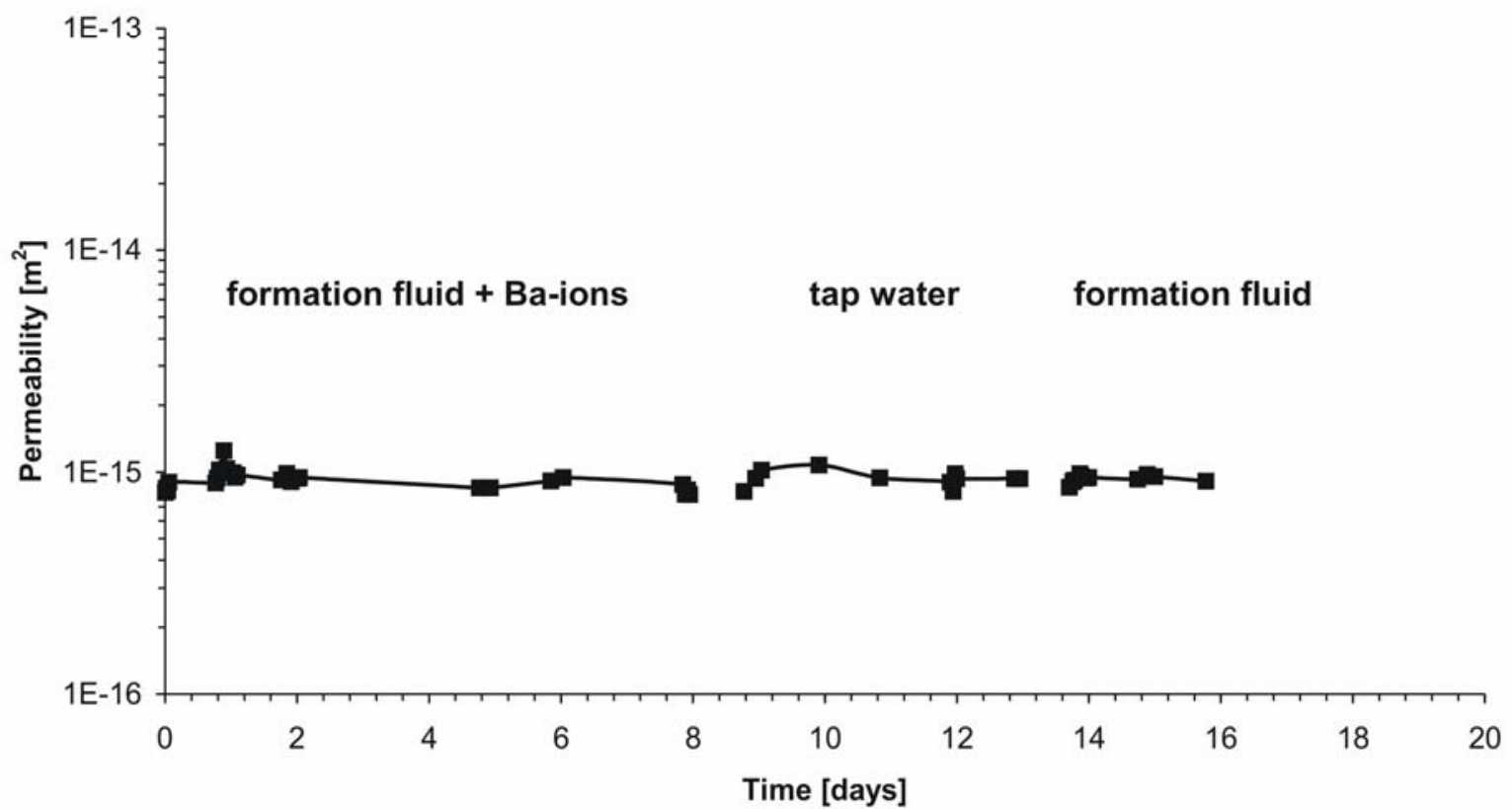

Figure 8 Sample ebe05-4, stage 2. Permeability as a function of time. Neither a change in temperature nor the different fluid exchanges affected the sample permeability which remained constant at approximately $1 \pm 0.1 \cdot 10^{-15} \mathrm{~m}^{2}$. 
ebe $05-4$ stage 2

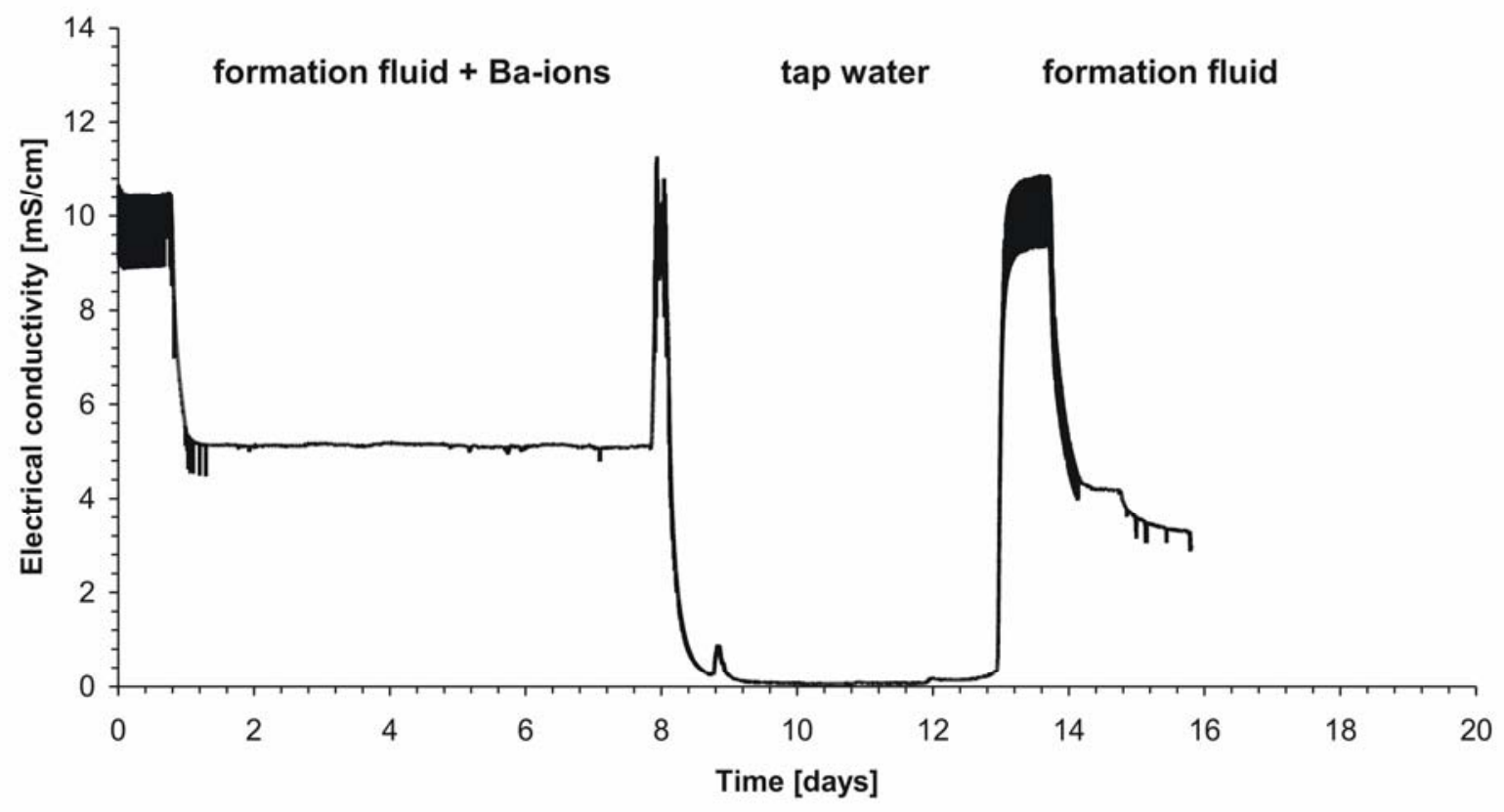

Figure 9 Sample ebe05-4, stage 2. Electrical conductivity as a function of time. At stable $\mathrm{p}-\mathrm{T}$ and fluid compositional conditions the electrical sample conductivity remained constant. Note the sharply alternating signal when flow was performed with the formation fluid at $150^{\circ} \mathrm{C}$. Also note that the exchange of formation fluid against tap water and vice versa took approximately 24 hours. This is significantly longer than expected for the given flow-rate $(0.1 \mathrm{~mL} / \mathrm{min})$ and the sample porosity $(11.1 \%)$. 
ebe05-4 Summary permeability evolution

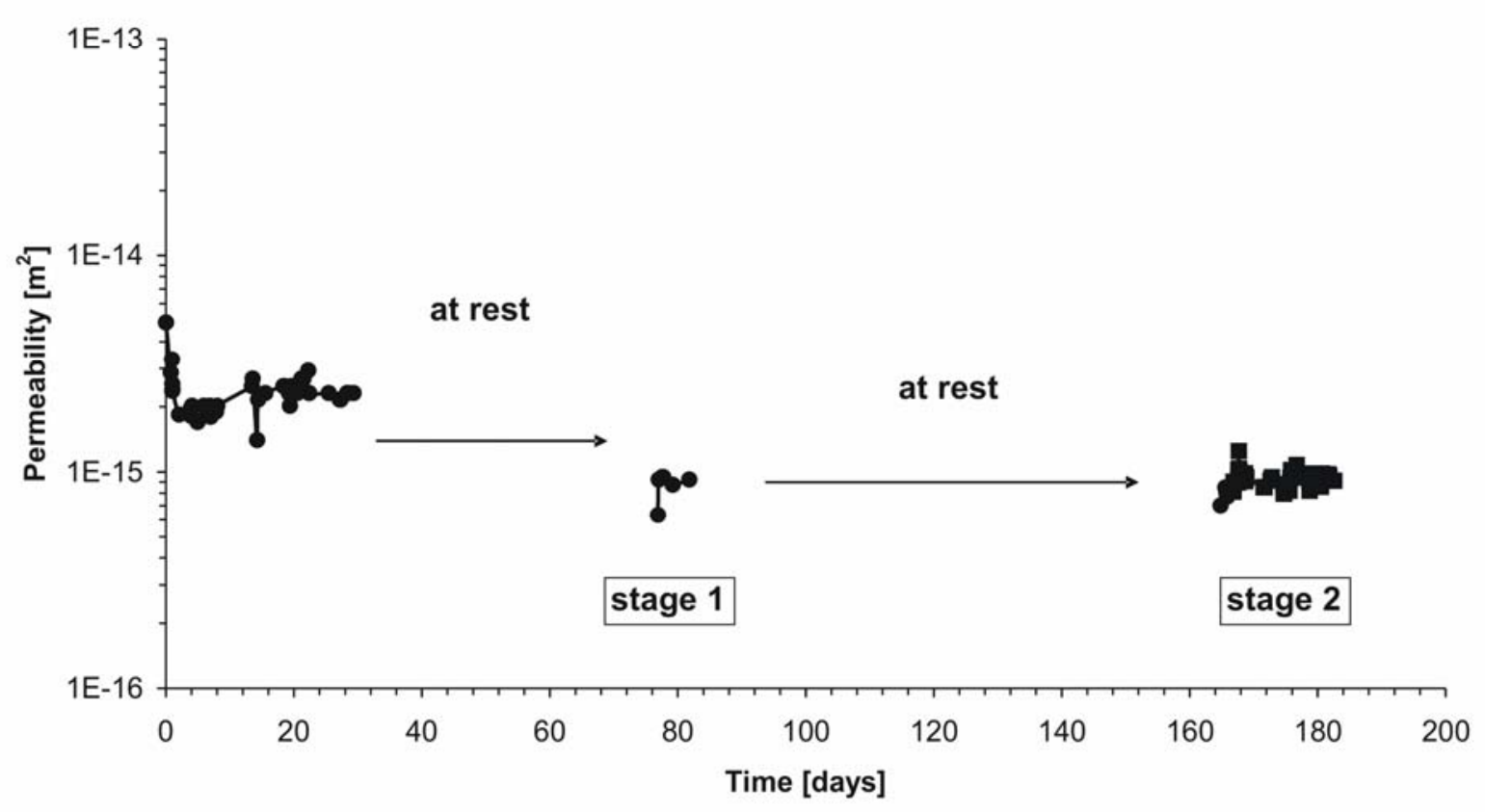

Figure 10 Sample ebe05-4, both stages. Summary of the permeability evolution of the sample as a function of time for comparison. 


\section{dp (formation fluid) and dp (water)}

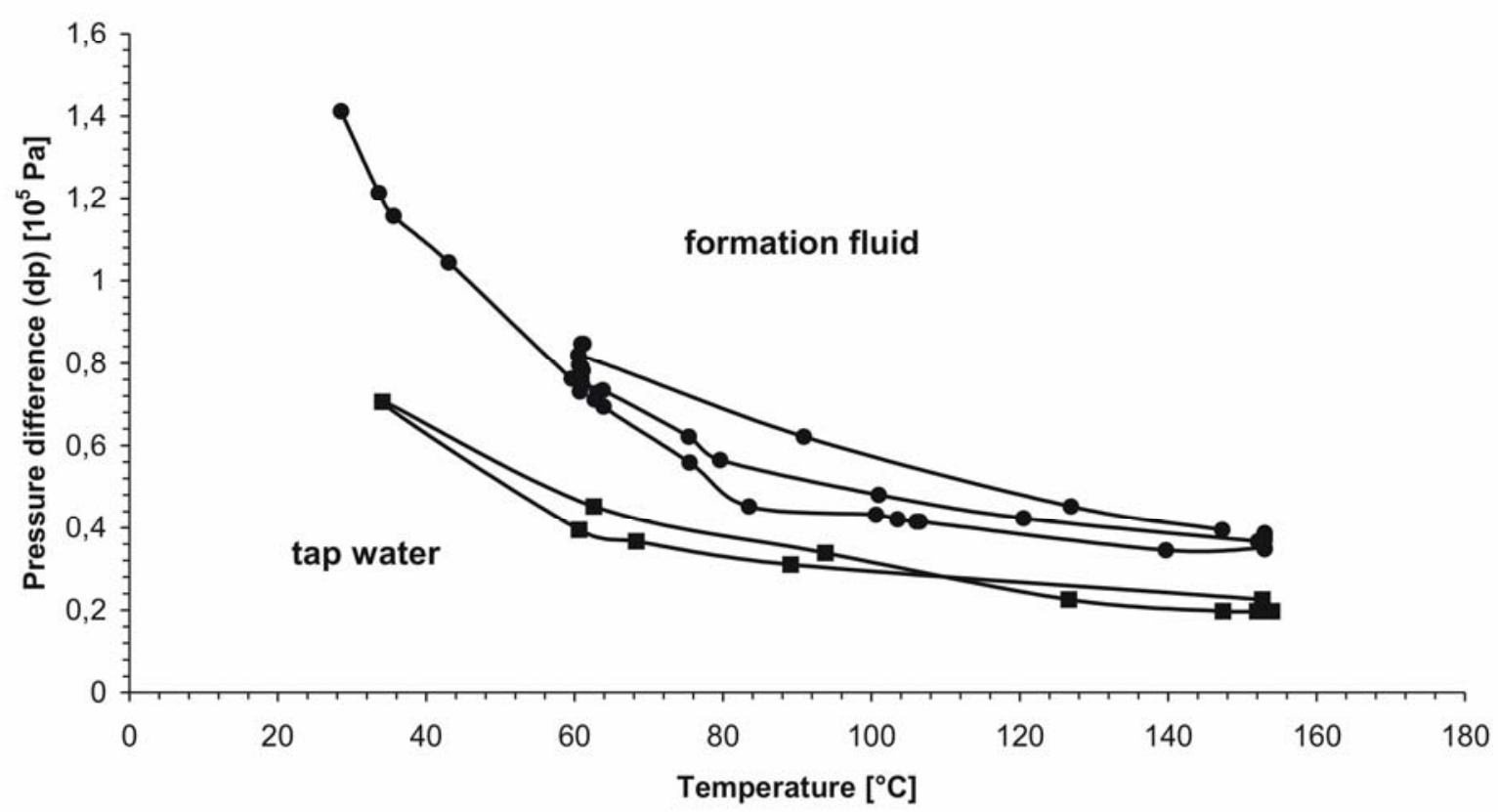

Figure 11 Sample ebe05-4. Pressure differences measured for both formation fluid and tap water during the fluid exchange procedure in stage 2 as a function of temperature. This data was used to calculate the unknown temperature dependence of the formation fluid viscosity (Figure 12) according to Equation (2) in Section 3.5. 
Viscosity (formation fluid) and Viscosity (water)

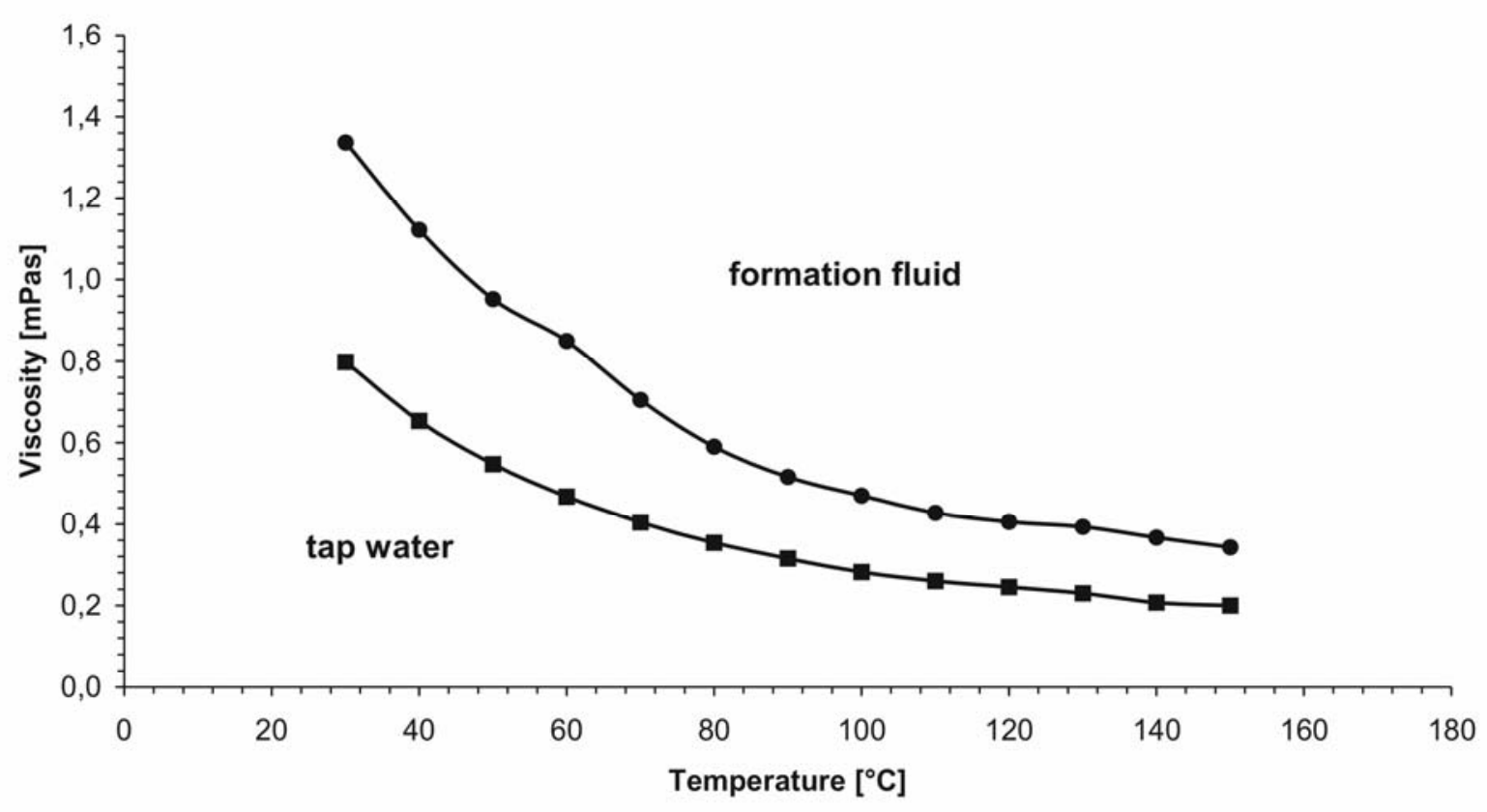

Figure 12 Sample ebe05-4. Viscosity of both formation fluid and tap water as a function of temperature. See Section 3.5 for more details. All permeability values presented in this paper were calculated according to the fluid-temperature conditions referring to one of the two graphs. 


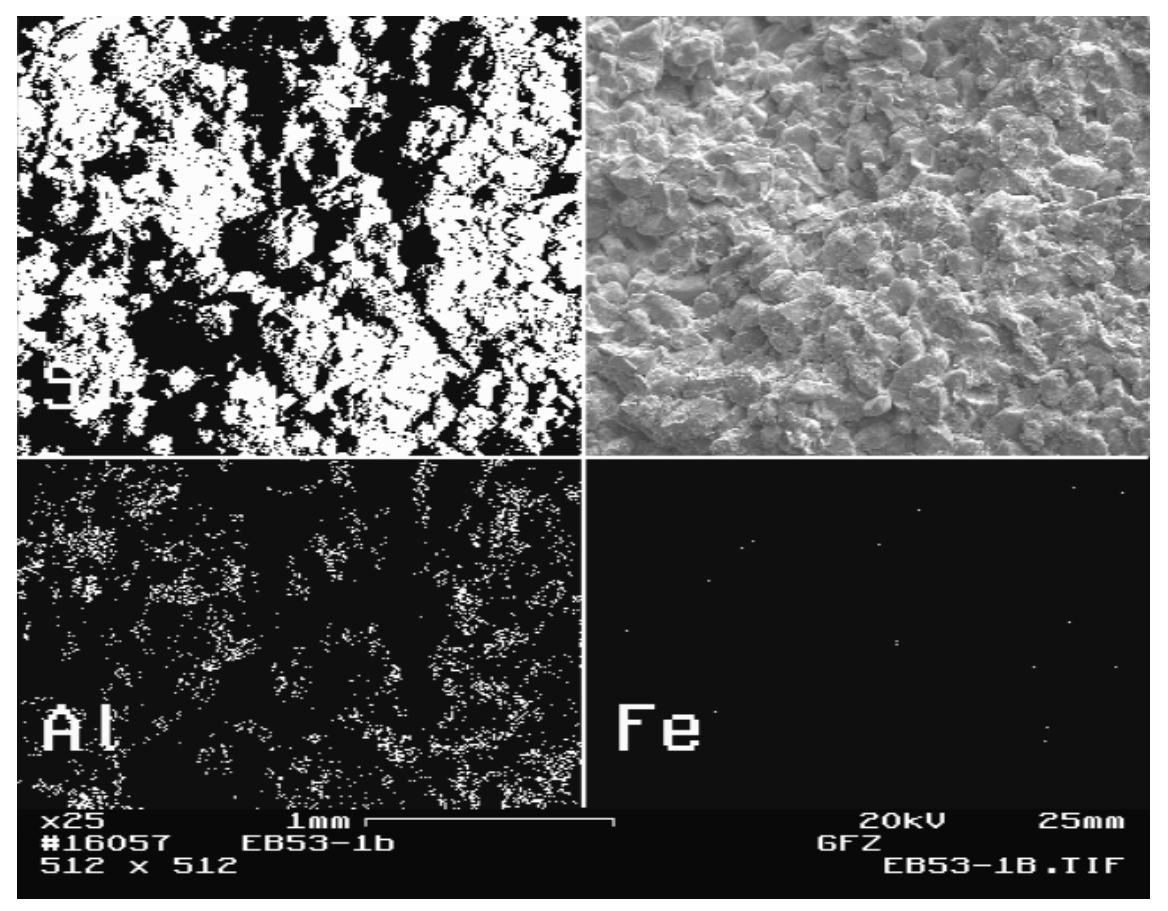

Figure 13 Results of post-experimental EDX element mapping for $\mathrm{Si}, \mathrm{Al}$ and $\mathrm{Fe}$ (sample ebe05-3). Si prevails due to the high quartz content of the sample. Al emanates from both K-feldspar and clay minerals (mainly illite and chlorite). The Fe content is very low and mainly related to smaller amounts of iron (III) oxide preserved on the quartz grains. See text for more details. 